\title{
Adaptive color space model based on dominant colors for image and video compression performance improvement
}

\author{
S. Madenda ${ }^{1}$, A. Darmayantie ${ }^{1}$ \\ ${ }^{1}$ Computer Engineering Department, Gunadarma University, \\ Jl. Margonda Raya. No. 100, Depok - Jawa Barat, Indonesia
}

\begin{abstract}
This paper describes the use of some color spaces in JPEG image compression algorithm and their impact in terms of image quality and compression ratio, and then proposes adaptive color space models (ACSM) to improve the performance of lossy image compression algorithm. The proposed ACSM consists of, dominant color analysis algorithm and $Y C_{o} C_{g}$ color space family. The $Y C_{o} C_{g}$ color space family is composed of three color spaces, which are $Y C_{c} C_{r}, Y C_{p} C_{g}$ and $Y C_{y} C_{b}$. The dominant colors analysis algorithm is developed which enables to automatically select one of the three color space models based on the suitability of the dominant colors contained in an image. The experimental results using sixty test images, which have varying colors, shapes and textures, show that the proposed adaptive color space model provides improved performance of $3 \%$ to $10 \%$ better than $Y C_{b} C_{r}, Y D_{b} D_{r}, Y C_{o} C_{g}$ and $Y C_{g} C_{o}-R$ color spaces family. In addition, the $Y C_{o} C_{g}$ color space family is a discrete transformation so its digital electronic implementation requires only two adders and two subtractors, both for forward and inverse conversions.

Keywords: colors dominant analysis, adaptive color space, image compression, image quality, compression ratio.

Citation: Madenda S, Darmayantie A. Adaptive color space model based on dominant colors for image and video compression performance improvement. Computer Optics 2021; 45(3): 405417. DOI: $10.18287 / 2412-6179-C O-780$.

Acknowledgments: Thank you to Gunadarma University for providing funding support during the research and publication process.
\end{abstract}

\section{Introduction}

Raw images and video frames recorded by highresolution cameras in information and communication technology (ICT) devices are in the form of three basic color components $R$ (red), $G$ (green) and $B$ (blue). These color components are called $R G B$ color spaces. Saving high-resolution raw images and video frames in $R G B$ color space requires enormous memory. Image and video compression algorithms are the main solutions to reduce data size and minimize storage requirements. JPEG and JPEG2000 are two compression algorithms that are widely used in ICT devices. In general, these two algorithms have the same process flow, as shown in fig. $1[1,2,3]$. The Compression algorithm in fig. $1 a$ consists of the following processes: color space conversion, spatial to frequency transform, quantization and coding. Contrary, the decompression algorithm (fig. $1 b$ ) consists of: decoding, inverse quantization, frequency to spatial transform and inverse color space conversion.

In image and video compression algorithms, the choice of color space is an important part, because it directly affects the compression ratio and image quality. This means that the use of the right color space can increase the compression ratio and image quality. Generally, the color space used is in accordance with the sensitivity of the human visual system to color changes, especially the color spaces that have luminance and chrominance components. The JPEG and JPEG2000 compression al- gorithms use color spaces $Y C_{b} C_{r}$ and $Y D_{b} D_{r}$, which $Y$ correspond to luminance, $C_{b}$ and $D_{b}$ are blue chrominance, and $C_{r}$ and $D_{r}$ are red chrominance components [3, 4, 5, 6]. The Color conversion process from $R G B$ to $Y C_{b} C_{r}$ can be calculated through a mathematical transformation as given in Eq. (1), while the inverse conversion process from $Y C_{b} C_{r}$ to $R G B$ is shown by Eq. (2). Matrix $A$ is called a color transformation matrix to which $\left[A^{-1}\right]$ is the inverse of matrix $[A]$ and is called an inverse color transformation matrix. Numerical implementation of $R G B$ to $Y C_{b} C_{r}$ conversion requires two shift-right operations, seven multiplications and six adders/subtractors. Numerical implementation of $Y C_{b} C_{r}$ to $R G B$ conversion requires four multiplications and four adders/subtractors. This color space is an irreversible color transform because it is rounded during the process.

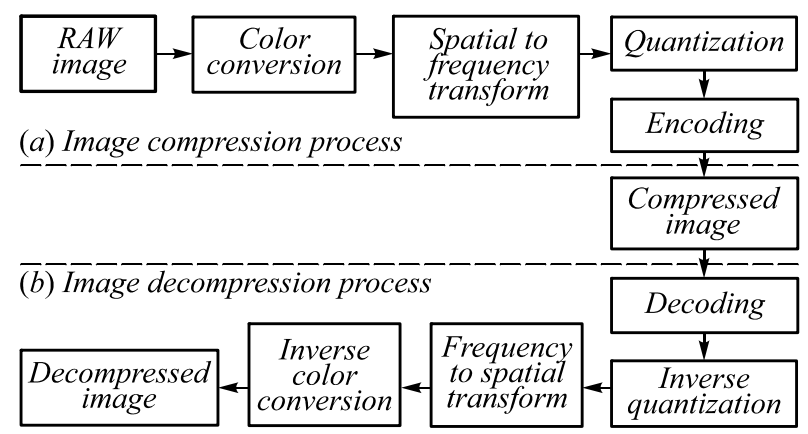

Fig. 1. General block diagram of JPEG and JPEG2000 algorithms: (a) Compression and (b) Decompression processes 


$$
\begin{aligned}
& {\left[\begin{array}{l}
Y \\
C_{b} \\
C_{r}
\end{array}\right]=[A]\left[\begin{array}{l}
R \\
G \\
B
\end{array}\right],[A]=\left[\begin{array}{ccc}
0.2990 & 0.5870 & 0.1140 \\
-0.1688 & -0.3312 & 0.5000 \\
0.5000 & -0.4187 & -0.0813
\end{array}\right],(1)} \\
& {\left[\begin{array}{l}
R \\
G \\
B
\end{array}\right]=\left[A^{-1}\right]\left[\begin{array}{l}
Y \\
C_{b} \\
C_{r}
\end{array}\right],\left[A^{-1}\right]=\left[\begin{array}{ccc}
1.0 & 0.0 & 1.4020 \\
1.0 & -0.3441 & -0.7141 \\
1.0 & 1.7720 & 0.0
\end{array}\right] .}
\end{aligned}
$$

The $Y D_{b} D_{r}$ color space used in the JPEG2000 compression algorithm is a variant of $Y C_{b} C_{r}$ [2, 7-9]. The matrices $[A]$ and $\left[A^{-1}\right]$ in Eqs. $(3,4)$ respectively show the transformation matrix for $R G B$ to $Y D_{b} D_{r}$ conversion and inverse transformation matrix for $Y D_{b} D_{r}$ to $R G B$ conversion. This color space is reversible color transform (RCT) and its numerical implementation is simpler because it only requires shift-right (symbolized by “»”), addition and subtraction operations, and without multiplication operation. For example, $0.5 \times \mathrm{R}$ is equal to one-bit shiftright of $\mathrm{R}$ value $(\mathrm{R} » 1)$ and $0.25 \times \mathrm{B}$ is identical to twobits shift-right of $\mathrm{B}$ value $\left(\mathrm{B} » 2\right.$ ). Thus, for $R G B$ to $Y D_{b} D_{r}$ conversion requires two shift-right operations and four adders / subtractors. While $Y D_{b} D_{r}$ to $R G B$ inverse conversion requires three shift-right and seven addition and subtraction operations.

$$
\begin{aligned}
& {\left[\begin{array}{l}
Y \\
D_{b} \\
D_{r}
\end{array}\right]=[A]\left[\begin{array}{l}
R \\
G \\
B
\end{array}\right],[A]=\left[\begin{array}{ccc}
0.25 & 0.50 & 0.25 \\
0.0 & -1.0 & 1.0 \\
1.0 & -1.0 & 0.0
\end{array}\right],} \\
& {\left[\begin{array}{l}
R \\
G \\
B
\end{array}\right]=\left[A^{-1}\right]\left[\begin{array}{l}
Y \\
D_{b} \\
D_{r}
\end{array}\right],\left[A^{-1}\right]=\left[\begin{array}{ccc}
1.0 & -0.25 & 0.75 \\
1.0 & -0.25 & -0.25 \\
1.0 & 0.75 & -0.25
\end{array}\right] .}
\end{aligned}
$$

Another variant of the $Y C_{b} C_{r}$ color space is $Y C_{o} C_{g}$, which has a conversion process easier and faster than $Y C_{b} C_{r}$, and it is a reversible color transform [9, 10]. $Y C_{o} C_{g}$ is also known as the $Y C_{g} C_{o}$ color model. The matrix $\mathrm{A}$ is used for the conversion process from $R G B$ to $Y C_{o} C_{g}$ and the inverse transformation matrix $\left[A^{-1}\right]$ is applied for the conversion process from $Y C_{o} C_{g}$ to $R G B$ which are given in Eqs. $(5,6)$. The numerical implementation of $R G B$ to $Y C_{o} C_{g}$ conversion requires four shiftright, two addition and tow subtraction operations. Likewise for $Y C_{o} C_{g}$ to $R G B$ conversion process requires only two addition and two subtraction operations.

$$
\begin{aligned}
& {\left[\begin{array}{l}
Y \\
C_{o} \\
C_{g}
\end{array}\right]=[A]\left[\begin{array}{l}
R \\
G \\
B
\end{array}\right],[A]=\left[\begin{array}{ccc}
0.25 & 0.50 & 0.25 \\
0.50 & 0.0 & -0.50 \\
-0.25 & 0.50 & -0.25
\end{array}\right],} \\
& {\left[\begin{array}{l}
R \\
G \\
B
\end{array}\right]=\left[A^{-1}\right]\left[\begin{array}{l}
Y \\
C_{o} \\
C_{g}
\end{array}\right],\left[A^{-1}\right]=\left[\begin{array}{ccc}
1.0 & 1.0 & -1.0 \\
1.0 & 0.0 & 1.0 \\
1.0 & -1.0 & -1.0
\end{array}\right] .}
\end{aligned}
$$

$Y C_{o} C_{g}$ color space is then developed into $Y C_{g} C-R$ with the aim to speed-up the conversion process by multiplying by 2 each value of the chrominance components [11,
12] (see Eqs. $(7,8)$ ). Numerical implementation of $R G B$ to $Y C_{g} C_{o}-\mathrm{R}$ conversion and its inverse conversion form $Y C_{g} C_{o}$ - $\mathrm{R}$ to $R G B$, both only require two shift-right, two addition and two subtraction operations.

$$
\begin{gathered}
{[A]=\left[\begin{array}{ccc}
0.25 & 0.50 & 0.25 \\
1.0 & 0.0 & -1.0 \\
-0.50 & 1.0 & -0.50
\end{array}\right],} \\
{\left[A^{-1}\right]=\left[\begin{array}{ccc}
1.0 & 0.5 & -0.5 \\
1.0 & 0.0 & 0.5 \\
1.0 & -0.5 & -0.5
\end{array}\right] .}
\end{gathered}
$$

In [13], the authors developed a new family of reversible low-complexity color transformation: $Y_{i} U V_{j}$. The $Y D_{b} D_{r}$ and $Y C_{g} C_{o}-R$ color spaces are included in this family. The $C_{o}=(\mathrm{R}-\mathrm{G}) / 2$ and $C_{g}=(2 \mathrm{G}-(\mathrm{R}+\mathrm{B})) / 4$ as chrominance components of $Y C_{o} C_{g}$ color space (Eq. 5) are not yet included. From this family, the color space components $Y_{i}, U_{j}$ and $V_{j}$, which have computational with lower complexity, are given in table 1 . The performance of each color space has been compared with the focus on lossy compression and by applying an automatic color space selection algorithm based on entropy $H$.

Table 1. $Y_{i} U V_{j}$ reversible color transformation.

\begin{tabular}{|c|c||r|c|c|}
\hline$i$ & $Y_{i}$ & $j$ & $U_{j}$ & $V_{j}$ \\
\hline 1 & $(\mathrm{R}+2 \mathrm{G}+\mathrm{B}) / 4$ & 1 & $\mathrm{G}-(\mathrm{R}+\mathrm{B}) / 2$ & $\mathrm{R}-\mathrm{B}$ \\
\hline 2 & $(\mathrm{R}+\mathrm{G}+2 \mathrm{~B}) / 4$ & 2 & $\mathrm{~B}-(\mathrm{R}+\mathrm{G}) / 2$ & $\mathrm{R}-\mathrm{G}$ \\
\hline 3 & $(2 \mathrm{R}+\mathrm{G}+\mathrm{B}) / 4$ & 3 & $\mathrm{R}-(\mathrm{G}+\mathrm{B}) / 2$ & $\mathrm{~B}-\mathrm{G}$ \\
\hline 4 & $(\mathrm{R}+\mathrm{G}) / 2$ & 4 & $\mathrm{~B}-(\mathrm{R}+\mathrm{G}) / 2$ & $\mathrm{R}-\mathrm{G}$ \\
\hline 5 & $(\mathrm{R}+\mathrm{B}) / 2$ & 5 & $\mathrm{G}-(\mathrm{R}+\mathrm{B}) / 2$ & $\mathrm{R}-\mathrm{B}$ \\
\hline 6 & $(\mathrm{R}+\mathrm{B}) / 2$ & 6 & $\mathrm{R}-(\mathrm{G}+\mathrm{B}) / 2$ & $\mathrm{~B}-\mathrm{G}$ \\
\hline
\end{tabular}

The image in $R, G$ and $B$ color components format must first be converted into each color component of $Y_{i}$, $U_{j}$, and $V_{j}$, and then the entropy value is calculated for each of $H\left(Y_{i}\right), H\left(U_{j}\right)$, and $H\left(V_{j}\right)$. It is assumed that the one having the smallest entropy value $\left(H=H\left(Y_{i}\right)+H\left(U_{j}\right)+H\left(V_{j}\right)\right)$, as the components of the color space, will be selected to be applied. To avoid high computation time, an image is divided into $p \times q$ macro blocks, where the number of blocks depends on the image size. For example, an image is divided into 9 blocks $(p=q=3)$, in each block the same components can be applied, or may also be different, according to their entropy calculation result. Both adaptive color space and macro block models have been developed in $[14,15]$ and implemented in 4: 4: 4 video coding.

The first three color spaces in table $1, Y_{1} U V_{1}, Y_{2} U V_{2}$ and $Y_{3} U V_{3}$ (each for $r=i=j$ is called $Y U V_{r}: Y U V_{l}, Y U V_{2}$, and $Y U V_{3}$ ), can be represented as matrix multiplication and each accompanied by its inverse transformation, respectively shown by Eqs. (9, 10, 11, 12, 13, 14). The $Y U V_{l}$ color space is the same as the $Y C_{g} C_{0}-R$ color space, while $Y U V_{2}$ and $Y U V_{3}$ are the permutations of the $Y U V_{1}$ color space. These three color spaces can be applied for lossless and lossy image compression.

$R G B$ to $Y U V_{l}$ and $Y U V_{l}$ to $R G B$ : 


$$
\begin{aligned}
& {\left[\begin{array}{l}
Y \\
U \\
V
\end{array}\right]=\left[A_{1}\right]\left[\begin{array}{l}
R \\
G \\
B
\end{array}\right] \text {, where }\left[A_{1}\right]=\left[\begin{array}{ccc}
0.25 & 0.5 & 0.25 \\
-0.5 & 1.0 & -0.5 \\
1.0 & 0.0 & -1.0
\end{array}\right],} \\
& {\left[\begin{array}{l}
R \\
G \\
B
\end{array}\right]=\left[A_{1}^{-1}\right]\left[\begin{array}{l}
Y \\
U \\
V
\end{array}\right] \text {, where }\left[A_{1}^{-1}\right]=\left[\begin{array}{ccc}
1.0 & -0.5 & 0.5 \\
1.0 & 0.5 & 0.0 \\
1.0 & -0.5 & -0.5
\end{array}\right] .}
\end{aligned}
$$

$R G B$ to $Y U V_{2}$ and $Y U V_{2}$ to $R G B$ :

$$
\begin{aligned}
& {\left[\begin{array}{l}
Y \\
U \\
V
\end{array}\right]=\left[A_{2}\right]\left[\begin{array}{l}
R \\
G \\
B
\end{array}\right] \text {, where }\left[A_{2}\right]=\left[\begin{array}{ccc}
0.25 & 0.25 & 0.5 \\
-0.5 & -0.5 & 1.0 \\
1.0 & -1.0 & 0.0
\end{array}\right],} \\
& {\left[\begin{array}{l}
R \\
G \\
B
\end{array}\right]=\left[A_{2}^{-1}\right]\left[\begin{array}{l}
Y \\
U \\
V
\end{array}\right] \text {, where }\left[A_{2}^{-1}\right]=\left[\begin{array}{ccc}
1.0 & -0.5 & 0.5 \\
1.0 & -0.5 & -0.5 \\
1.0 & 0.5 & 0.0
\end{array}\right] .}
\end{aligned}
$$

$R G B$ to $Y U V_{3}$ and $Y U V_{3}$ to $R G B$ :

$$
\begin{aligned}
& {\left[\begin{array}{l}
Y \\
U \\
V
\end{array}\right]=\left[A_{3}\right]\left[\begin{array}{l}
R \\
G \\
B
\end{array}\right] \text {, where }\left[A_{3}\right]=\left[\begin{array}{ccc}
0.5 & 0.25 & 0.25 \\
1.0 & -0.5 & -0.5 \\
0.0 & -1.0 & 1.0
\end{array}\right],} \\
& {\left[\begin{array}{l}
R \\
G \\
B
\end{array}\right]=\left[A_{3}^{-1}\right]\left[\begin{array}{l}
Y \\
U \\
V
\end{array}\right] \text {, where }\left[A_{3}^{-1}\right]=\left[\begin{array}{ccc}
1.0 & 0.5 & 0.0 \\
1.0 & -0.5 & -0.5 \\
1.0 & -0.5 & 0.5
\end{array}\right] .}
\end{aligned}
$$

\section{Performance evaluation of existing color spaces}

In terms of numerical implementation, it can be concluded that $Y U V_{l}\left(=Y C_{o} C_{g}-\mathrm{R}\right), Y U V_{2}$ and $Y U V_{3}$ are simpler and faster than $Y C_{o} C_{g}, Y D_{b} D_{r}$ and $Y C_{b} C_{r}$ color spaces. So, what about the performance in terms of compression ratio and image quality, if each color space is implemented in the lossy image compression algorithm?

In this part, we describe performance evaluation of color spaces $Y C_{b} C_{r}, Y D_{b} D_{r}, Y C_{o} C_{g}, Y U V_{l}, Y U V_{2}$ and $Y U V_{3}$, applied in JPEG compression algorithm. As known that image quality and compression ratio of color image compression algorithms are not only determined by the diversity of color contained in an image, but also influenced by texture and shape variations. For these reasons, in the experiments, 60 images were selected containing various colors, shapes and textures from six sources of image dataset $[16,17,18,19,20,21]$. Twelve of them are shown in fig. 2. For example, the Lena image has the dominant colors red, orange and red-purple, many homogeneous areas, slight in texture and shape variation. The Baboon image has random textures and shapes, and its dominant colors are green-yellow, cyan and red. The Frymire image is very rich in textures and shapes, as well as containing variant colors with almost the same composition between yellow, red, orange, green, cyan, blue and purple. The Roses image has dominant colors red, redpurple (pink), blue-cyan, blue-purple, yellow, white and

black. The Woman image has a little color variation, some areas are relatively homogeneous and varying texture patterns in the hair. Yellow_orchid has a dominant homogeneous area, yellow and cyan colors, as well as various shapes and slight variations in texture.
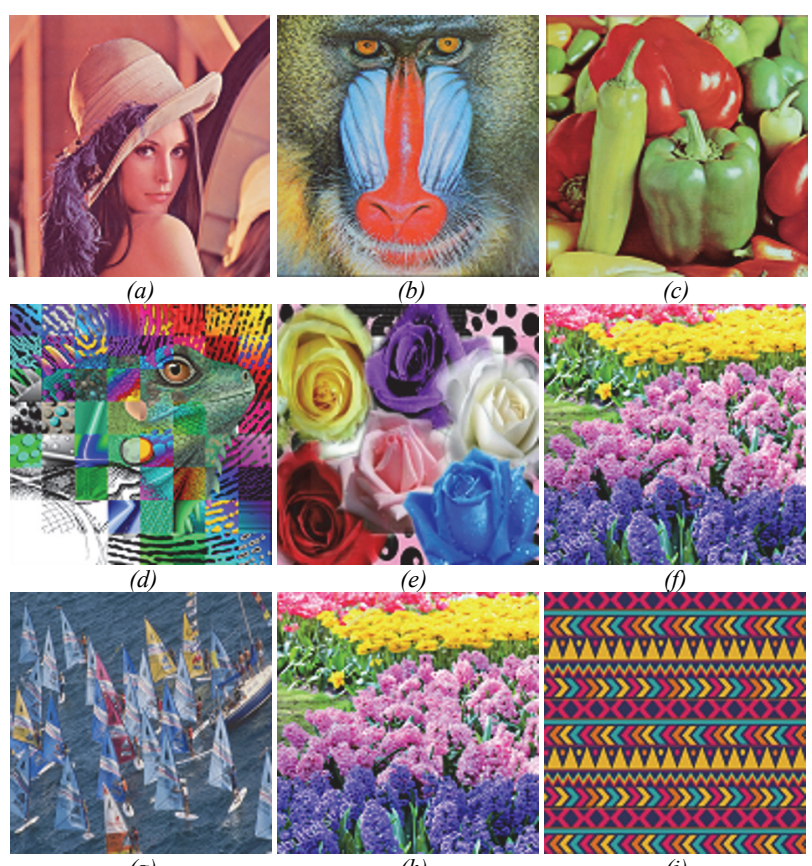

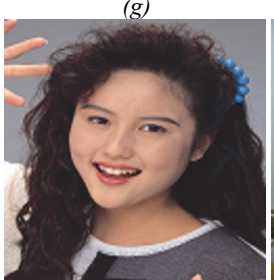

(j)
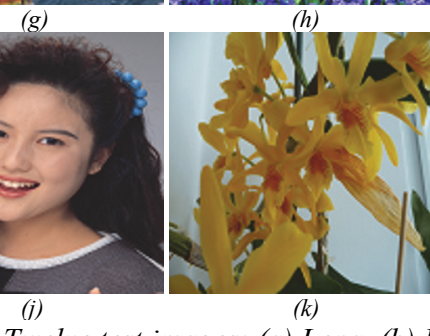

Fig. 2. Twelve test images: (a) Lena, (b) Baboon, (c) Peppers

(d) Frymire, (e) Roses, (f) Tulips, (g) Sails, (h) Monarch,

(i) Textile, (j) Woman, (k) yellow_orchid, and (l) ucid00295

Next, we outline the performance comparison of six color space $Y C_{b} C_{r}, Y D_{b} D_{r}, Y C_{o} C_{g}, Y U V_{l}, Y U V_{2}$ and $Y U V_{3}$, regarding their compression ratio and image quality, when each of them is used in the lossy image compression algorithm. Block size $8 \times 8$ pixels [1], color components without sub-sampling for high quality image compression $[23,24,25]$, discrete cosine transform $(8 \times 8$ DCT and iDCT) $[1,26,27,28,29]$, and Huffman statistic encoding/decoding $[1,2,8,22,30]$ are chosen to carryout the experiments of JPEG lossy image compression. For each color space used, it is done by determining the same quality for the same image and then compares their compression ratio. In this case, the experiment was carried out by using one Photoshop's quantization matrix for medium quality $\left(\mathrm{Q}_{9}\right)$ as shown in Eq. $(15)[3,22]$. $Q_{\text {Lum }}$ and $\mathrm{Q}_{\mathrm{Cr}}$ are respectively quantization matrices for luminance and chrominance components, and $q$ is a variable that determines the quantization value, so that the seven color spaces can produce the same quality for the same image, thus the compression ratio can be compared. 


$$
Q_{C r}=q \cdot\left[\begin{array}{cccccccc}
4 & 6 & 12 & 22 & 20 & 20 & 17 & 17 \\
6 & 8 & 12 & 14 & 14 & 12 & 12 & 12 \\
12 & 12 & 14 & 14 & 12 & 12 & 12 & 12 \\
22 & 14 & 14 & 12 & 12 & 12 & 12 & 12 \\
20 & 14 & 12 & 12 & 12 & 12 & 12 & 12 \\
20 & 12 & 12 & 12 & 12 & 12 & 12 & 12 \\
17 & 12 & 12 & 12 & 12 & 12 & 12 & 12 \\
17 & 12 & 12 & 12 & 12 & 12 & 12 & 12
\end{array}\right]
$$

and

$$
Q_{\text {Lum }}=q \cdot\left[\begin{array}{cccccccc}
4 & 3 & 4 & 7 & 9 & 11 & 14 & 17 \\
3 & 3 & 4 & 7 & 9 & 12 & 12 & 12 \\
4 & 4 & 5 & 9 & 12 & 12 & 12 & 12 \\
7 & 7 & 9 & 12 & 12 & 12 & 12 & 12 \\
9 & 9 & 12 & 12 & 12 & 12 & 12 & 12 \\
11 & 12 & 12 & 12 & 12 & 12 & 12 & 12 \\
14 & 12 & 12 & 12 & 12 & 12 & 12 & 12 \\
17 & 12 & 12 & 12 & 12 & 12 & 12 & 12
\end{array}\right]
$$

Table 2. Compression ratio of nine images using JPEG

\begin{tabular}{|c|c|c|c|c|c|c|c|}
\hline \multirow{2}{*}{$\begin{array}{c}\text { File Image } \\
\text { (png) }\end{array}$} & \multirow{2}{*}{$\begin{array}{c}\text { Quali- } \\
\text { ty } \\
\text { PSNR } \\
\text { (dB) }\end{array}$} & \multicolumn{6}{|c|}{$\begin{array}{c}\text { Compression Ratio (CR) } \\
\text { Using Color Space: }\end{array}$} \\
\hline & & $Y C_{b} C_{r}$ & $Y D_{b} D_{r}$ & $Y C_{o} C_{g}$ & $\begin{array}{c}\boldsymbol{Y U} \boldsymbol{V}_{1} \\
\boldsymbol{Y C} \boldsymbol{C}_{\boldsymbol{o}} \boldsymbol{C}_{g-} \\
\mathbf{R}\end{array}$ & $Y U V_{2}$ & $\boldsymbol{Y U} \boldsymbol{V}_{3}$ \\
\hline Lena & 36.117 & 9.490 & 8.430 & 10.024 & 8.910 & 7.987 & 9.076 \\
\hline Baboon & 32.805 & 3.554 & 3.486 & 3.798 & 3.543 & 3.446 & 3.506 \\
\hline Peppers & 34.057 & 6.161 & 5.952 & 6.580 & 6.230 & 6.419 & 5.995 \\
\hline Frymire & 34.227 & 3.696 & 3.500 & 3.765 & 3.577 & 3.585 & 3.597 \\
\hline Roses & 46.776 & 19.96 & 19.118 & 19.709 & 18.960 & 19.213 & 19.340 \\
\hline Tulips & 33.764 & 3.784 & 3.405 & 3.679 & 3.500 & 3.669 & 3.601 \\
\hline Sails & 37.456 & 7.451 & 7.228 & 7.750 & 7.220 & 7.081 & 7.013 \\
\hline Monarch & 39.788 & \multicolumn{3}{|c|}{$12.28811 .560 \mathbf{1 2 . 5 5 3}$} & 11.834 & 11.788 & 11.702 \\
\hline Textile & 36.838 & 5.442 & 5.422 & 5.464 & 5.280 & 5.439 & 5.166 \\
\hline Woman & 38.011 & \multicolumn{3}{|c|}{\begin{tabular}{|l|l|l|l|}
10.156 & 10.400 & $\mathbf{1 0 . 4 4 2}$ \\
\end{tabular}} & 9.021 & 8.862 & 9.062 \\
\hline Yellow_Or & 41.050 & \multicolumn{3}{|c|}{21.39822 .91523 .518} & 23.355 & 24.131 & 22.996 \\
\hline Ucid00295 & 36.614 & 7.642 & 7.794 & 7.908 & 7.228 & 7.086 & 7.174 \\
\hline CR Aver & rage & 9.252 & 9.101 & 9.599 & 9.055 & 9.059 & 9.019 \\
\hline \multicolumn{3}{|c|}{$\begin{aligned} \text { Note: } & \uparrow \text { Increase } \\
& \downarrow \text { Decrease }\end{aligned}$} & & & $\downarrow 2.1 \%$ & $\downarrow 2.1 \%$ & $\downarrow 2.5 \%$ \\
\hline
\end{tabular}
algorithm for six color spaces

Table 2 shows the compression ratio (CR) of JPEG algorithm using color spaces: $Y C_{b} C_{r}, Y D_{b} D_{r}, Y C_{o} C_{g}$, $Y U V_{1}, Y U V_{2}$ and $Y U V_{3}$. In the first line, for Lena image with compression quality of $\mathrm{PSNR}=36.117 \mathrm{~dB}$, the $\mathrm{CR}$ produced by $Y C_{b} C_{r}$ is $9.490, Y D_{b} D_{r}$ is $8.430, Y C_{o} C_{g}$ is 10.024 and respectively for $Y U V_{1}, Y U V_{2}$ and $Y U V_{3}$ are 8.910, 7.987, and 9.076. Similarly, for Baboon image in the second row with a compression quality of PSNR $=32.805 \mathrm{~dB}$, six consecutive color spaces produced CR of: 3.554, 3.486, 3.798, 3.543, 3.446 and 3.506. Furthermore, the CR for Peppers, Frymire, Roses, Tulips, Sails, Monarch, Textile, Woman, yellow_orchid and ucid00295 images can be seen in the next lines.

From the compression ratio results in table 2, it can be seen that, $Y C_{o} C_{g}$ color space yields highest CR for Lena, Baboon, Peppers, Frymire, Sails, Monarch, Woman and
Ucid00295 images compared to the five others. $Y C_{b} C_{r}$ results in better CR for Roses and Tulips images, while Yellow_Orchid image has highest CR given by $Y U V_{2}$. In the two last rows of table 2, the CR average and the performance produced by each color space is given. When referring to these $\mathrm{CR}$ average values and comparing them to the $\mathrm{CR}$ average value of JPEG-standard $Y C_{b} C_{r}$ color space, $Y C_{o} C_{g}$ provides better performance with increased CR of $3.8 \%$ on average, while $Y D_{b} D_{r}, Y U V_{1}, Y U V_{2}$ and $Y U V_{3}$ resulted $\mathrm{CR}$ averages of $1.6 \%, 2.1 \%, 2.1 \%$, and $2.5 \%$ lower than $Y C_{b} C_{r}$ respectively.

The experimental results of the other forty-eight images are given in tables $4-5$. Table 4 represents the compression ratios for the same image quality and table 5 reflects the image quality for the same compression ratio. For now, we focus on the first seven columns to evaluate the compression results of the forty-eight images using $Y C_{b} C_{r}, Y C_{o} C_{g}, Y U V_{1}, Y U V_{2}$ and $Y U V_{3}$ color spaces. There are thirty-seven images $(75.51 \%)$ that have the highest compression ratio and image quality generated by the $Y C_{o} C_{g}$ color space (in the fourth column), nine images $(18.37 \%)$ given by the $Y C_{b} C_{r}$ color space (in the third column), and the remaining two, one and zero images respectively resulted by $Y U V_{1}, Y U V_{2}$ and $Y U V_{3}$ color spaces (in the fifth, sixth and seventh column). In the last two rows of each table, the $\mathrm{CR}$ average and the performance yielded by each color space is given. $Y C_{o} C_{g}$ color space has the highest average value of 9.599, followed by $Y C_{b} C_{r}=9.252, Y D_{b} D_{r}=9.101, Y U V_{2}=9.059, Y U V_{l}=9.055$ and $Y U V_{2}=9.019$. These $\mathrm{CR}$ average values show that for those forty-eight images, the use of $Y C_{o} C_{g}$ in the JPEG lossy compression algorithm can increase the $\mathrm{CR}$ average of $3.623 \%$, while for $Y U V_{1}, Y U V_{2}$ and $Y U V_{3}$ there is a decrease of $3.158 \%, 5.056 \%$ and $4.693 \%$ respectively.

These results indicate that in general $Y C_{o} C_{g}$ color space provides better performance than the five other color spaces and $Y C_{b} C_{r}$ has a higher compression ratio than $Y U V_{1}, Y U V_{2}, Y U V_{3}$ and $Y D_{b} D_{r}$ color spaces. It may be assumed that the compatibility between the percentage composition of each color in a color space formula and the dominant colors contained in an image can affect the quality and compression ratio. The first analysis is about the percentage of color representation in a color space formula. For example, a pixel has pure red or pure blue, in $Y C_{o} C_{g}$ color space, its color will be accommodated $100 \%$ (25\% in Y, $50 \%$ in $C_{o}$ and $25 \%$ in $C_{g}$ components), while in $Y C_{b} C_{r}, Y D_{b} D_{r}$ and $Y C_{g} C_{o}-R$ family $\left(Y U V_{1}, Y U V_{2}, Y U V_{3}\right)$ color spaces respectively accommodate $97.775 \%, 125 \%$ and $175 \%$. Furthermore, for pure green, it will be recorded $100 \%, 250 \%, 150 \%$ and $133.695 \%$ respectively by $Y C_{o} C_{g}, Y C_{b} C_{r}, Y D_{b} D_{r}$ and $Y C_{o} C_{g}-R$. Ideally to get good quality and compression ratio, the color conversion formula must still record $100 \%$ of the dynamic value for each color component $\mathrm{R}, \mathrm{G}$ and B. This ideal condition is only owned by $Y C_{o} C_{g}$ color space and it is proven that its performance is better than the three other color spaces. The second analysis con- 
cerns chrominance covered by the color space formula. For example, $Y C_{b} C_{r}$ color space tends to be dominant in color combinations with hues (for all chrominance and luminance): red, orange, yellow, green, green-yellow, cyan, and blue, whereas the $Y C_{o} C_{g}$ color space covers more color variations with hues: red, orange, green-yellow, green, green-cyan, blue, purple. This means, there are several hues that have not been well covered by each color space formula. The third analysis is the compatibility between the color space used and the dominant colors contained in an image. Based on the three thoughts above, this paper proposes a color dominant analysis algorithm and an adaptive color space model.

\section{Proposed methods}

The proposed methods consist of three parts: developing adaptive color space, analyzing dominant colors in an image to determine which color space will be used, and then the experimentations. The development of adaptive color space model refers to $Y C_{o} C_{g}$ color space which provides better quality and compression ratio in lossy image compression (see results in table 1). It has been described above that this color space has not evenly covered all existing chrominance. This weakness has an impact on quality and compression ratio: it is best suited for images having colors according to their characteristics and decreased for images having less suitable color.

\subsection{Dominant colors analysis}

As described in the example of twelve images (fig. 2), where each image has a different dominant color. Thus, there is a need to adapt the suitability of the color space used and the image to be compressed. For this reason, the dominant color analysis contained in the image must be carried out first. The colors information can be presented in the form of cylindrical coordinates hue-saturation as shown in fig. $3 a$. We propose to divide hue coordinates into 12 parts, so that 12 different hues will be formed with angle range: $\mathrm{red}=0^{\circ}-$ $15^{\circ}$ and $345^{\circ}-360^{\circ}$, orange $=15^{\circ}-45^{\circ}$, yellow $=45^{\circ}-75^{\circ}$, green-yellow $=75^{\circ}-105^{\circ}, \quad$ green $=105^{\circ}-135^{\circ}, \quad$ greencyan $=135^{\circ}-165^{\circ}, \quad$ cyan $=165^{\circ}-195^{\circ}, \quad$ blue-cyan $=195^{\circ}$ $225^{\circ}$, blue $=225^{\circ}-255^{\circ}$, blue-purple $=255^{\circ}-285^{\circ}$, purple $=285^{\circ}-315^{\circ}$, red-purple $=315^{\circ}-345^{\circ}$. (a)

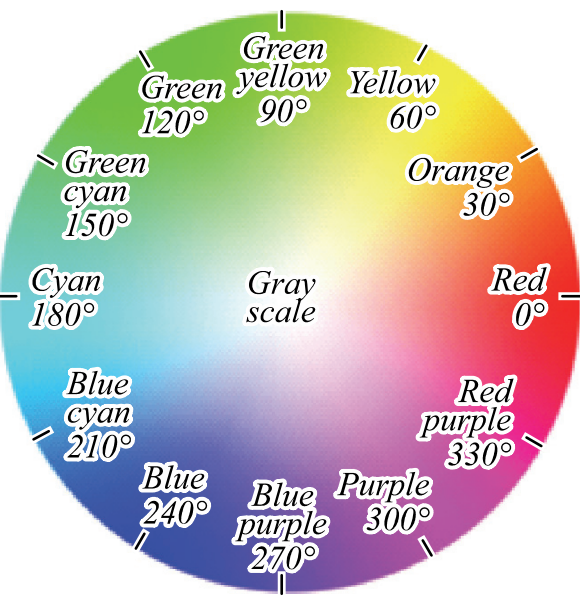

(b)

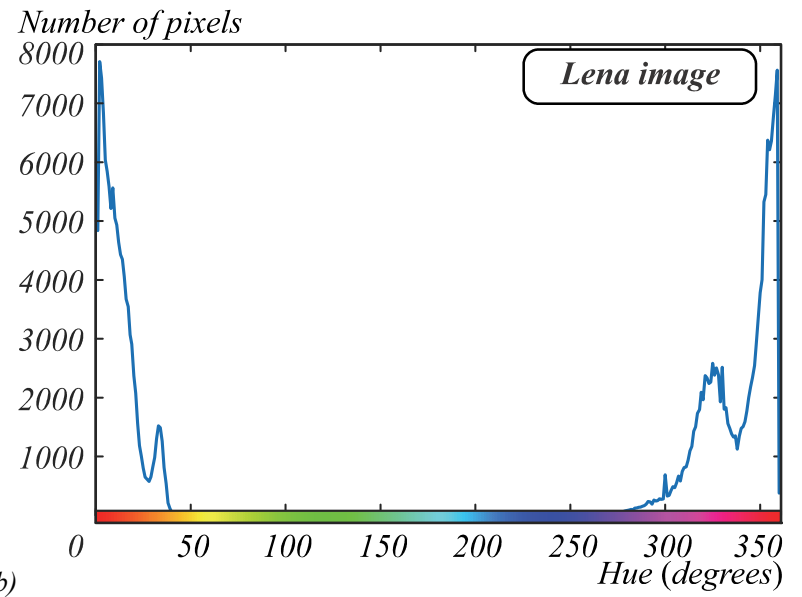

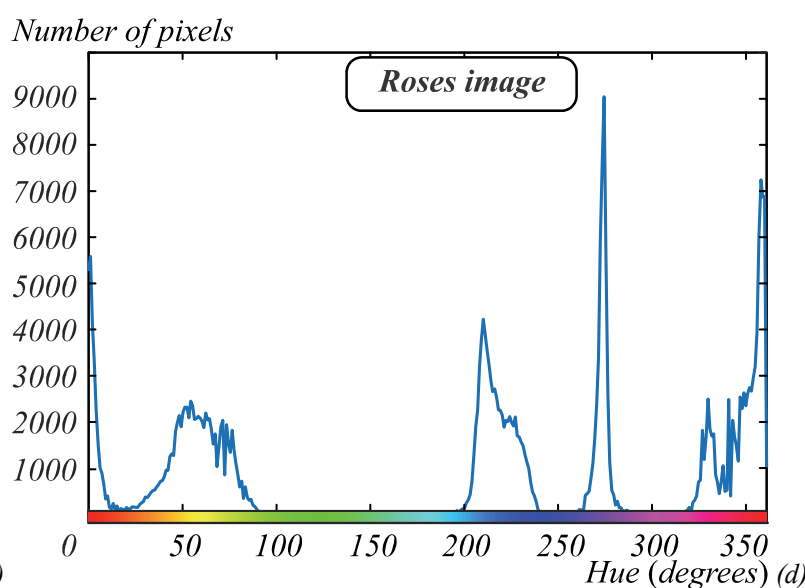

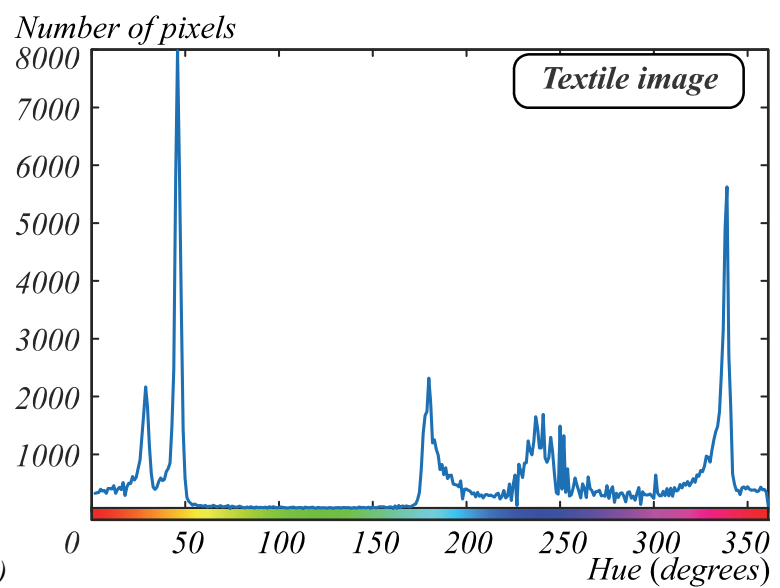

Fig. 3. (a) Cylindrical coordinates of hue; and hue histograms of (b) Lena, (c) Roses and (d) Textile images

The Hue of each pixel of an $R G B$ image can be calculated using $\mathrm{H}$ (hue) component formula of HSL, HSV or HCL color spaces $[31,32]$. From the hue value of each pixel, a histogram hue can be calculated. A Histo- gram hue is a distribution of the number of pixels having the same hue value in an image. Furthermore, this histogram hue can be used to determine what chrominance are dominants in an image. figs. $3 b-d$ respective- 
ly show histogram hues for Lena, Roses, and Textile images. The dominant hue in Lena image is red, orange, and red-purple. These three hues are more in line with $Y C_{o} C_{g}$ that is why its compression ratio performance is $5.63 \%$ better than $Y C_{b} C_{r}$ (see table 2). Roses image has dominant hues: red, red-purple, blue-cyan, blue-purple, yellow, white, and black. The majority of these hues are less compatible with $Y C_{o} C_{g}$, this has an impact on decreasing its compression ratio performance to $1.27 \%$ lower than $Y C_{b} C_{r}$. For Textile images, its dominant hues are yellow, orange, cyan, blue, red-purple. For this Textile image, $Y C_{o} C_{g}$ and $Y C_{b} C_{r}$ provide a relatively similar compression ratio.

The proposed algorithm for the dominant colors analysis process in an image is given in Algo-1. The syntax of Hue histo(red), Hue_histo(cyan), and so on represent the number of pixels in an image that have the red hues $\left(0^{\circ}-15^{\circ}\right.$ and $\left.345^{\circ}-360^{\circ}\right)$, cyan hues $\left(165^{\circ}-\right.$ $195^{\circ}$ ), and so forth. The dominant colors are grouped into three parts according to the three color space models described in section 3.2. The first part (Model-1) is a combination of red, cyan, green-yellow, blue-purple, and gray-level colors. The second part (Model-2) is a combination of green, purple, orange, blue-cyan, and gray-level colors. The last part (Model-3) is a combination of blue, yellow, green-cyan, red-purple, and gray-level colors.

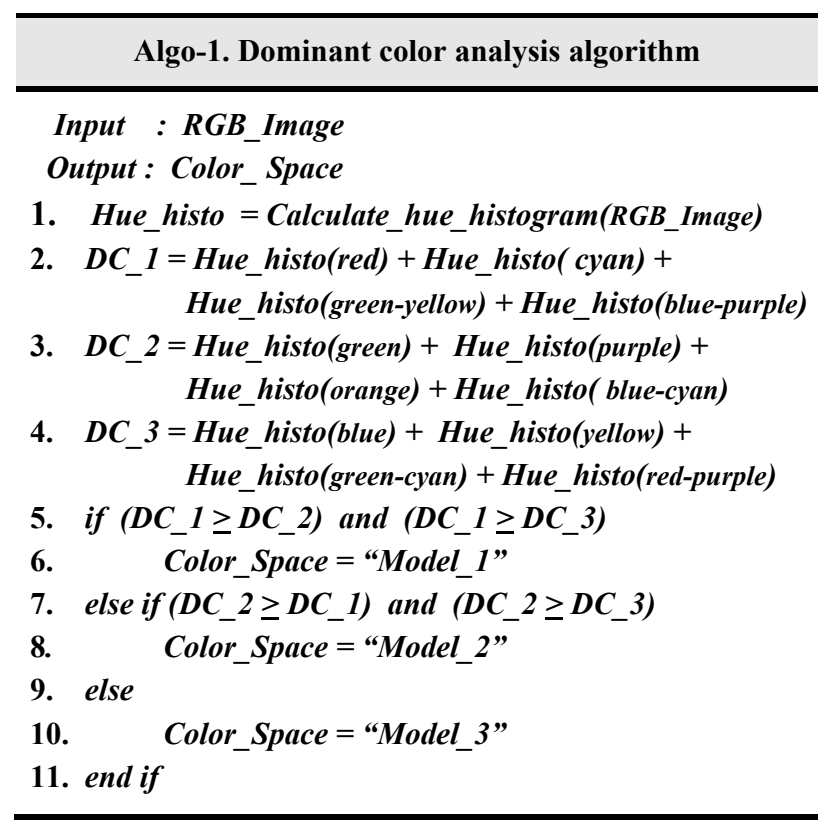

\subsection{Proposed adaptive color space model}

In this part, we adopted the permutation model proposed in [13] to produce two additional color spaces which are variants of $Y C_{o} C_{g}$ and to be a solution to its weaknesses. The two color spaces are shown in Eqs. (16, $17)$, and Eqs. $(20,21)$. Thus, the proposed adaptive color space model (ACSM) consists of three color spaces and can be said as the $Y C_{o} C_{g}$ color space family (ACSM$\left.Y C_{o} C_{g}\right)$. As a side note, if each of their all chrominance components is multiplied by 2, they will be identical to the $Y C_{g} C_{o}$-R color space family $\left(Y U V_{l}, Y U V_{2}\right.$ and $\left.Y U V_{3}\right)$.

Model-1: $Y C_{c} C_{r}$ (luminance $Y$, chrominance cyan $C_{c}$ and chrominance red $C_{r}$ ) with dominant hues (colors) coverage: red, cyan, green-yellow, blue-purple, and grey-level.

$$
\begin{aligned}
& {\left[\begin{array}{l}
Y \\
C_{c} \\
C_{r}
\end{array}\right]=[A]\left[\begin{array}{l}
R \\
G \\
B
\end{array}\right],[A]=\left[\begin{array}{ccc}
0.50 & 0.25 & 0.25 \\
0.0 & 0.50 & -0.50 \\
0.50 & -0.25 & -0.25
\end{array}\right],} \\
& {\left[\begin{array}{l}
R \\
G \\
B
\end{array}\right]=\left[A^{-1}\right]\left[\begin{array}{l}
Y \\
C_{c} \\
C_{r}
\end{array}\right],\left[A^{-1}\right]=\left[\begin{array}{ccc}
1.0 & 1.0 & -1.0 \\
1.0 & -1.0 & -1.0 \\
1.0 & 0.0 & 1.0
\end{array}\right] .}
\end{aligned}
$$

Model-2: $Y C_{p} C_{g}$ (luminance $Y$, chrominance purple $C_{p}$ and chrominance green $C_{g}$ ) is equal to $Y C_{o} C_{g}$ (Eq. 5) with dominant hues coverage: green, purple, orange, blue-cyan, and grey-level.

$$
\begin{aligned}
& {\left[\begin{array}{l}
Y \\
C_{p} \\
C_{g}
\end{array}\right]=[A]\left[\begin{array}{l}
R \\
G \\
B
\end{array}\right],[A]=\left[\begin{array}{ccc}
0.25 & 0.50 & 0.25 \\
0.50 & 0.0 & -0.50 \\
-0.25 & 0.50 & -0.25
\end{array}\right],} \\
& {\left[\begin{array}{l}
R \\
G \\
B
\end{array}\right]=\left[A^{-1}\right]\left[\begin{array}{l}
Y \\
C_{p} \\
C_{g}
\end{array}\right],\left[A^{-1}\right]=\left[\begin{array}{ccc}
1.0 & 1.0 & -1.0 \\
1.0 & 0.0 & 1.0 \\
1.0 & -1.0 & -1.0
\end{array}\right] .}
\end{aligned}
$$

Model-3: $Y C_{y} C_{b}$ (luminance $Y$, chrominance yellow $C_{y}$ and chrominance blue $C_{b}$ ) with dominant hues coverage: blue, yellow, green-cyan, red-purple, and grey-level.

$$
\begin{aligned}
& {\left[\begin{array}{l}
Y \\
C_{y} \\
C_{b}
\end{array}\right]=[A]\left[\begin{array}{l}
R \\
G \\
B
\end{array}\right],[A]=\left[\begin{array}{ccc}
0.25 & 0.25 & 0.50 \\
0.50 & -0.50 & 0.0 \\
-0.25 & -0.25 & 0.5
\end{array}\right],} \\
& {\left[\begin{array}{l}
R \\
G \\
B
\end{array}\right]=\left[A^{-1}\right]\left[\begin{array}{l}
Y \\
C_{y} \\
C_{b}
\end{array}\right],\left[A^{-1}\right]=\left[\begin{array}{ccc}
1.0 & 1.0 & -1.0 \\
1.0 & -1.0 & -1.0 \\
1.0 & 0.0 & 1.0
\end{array}\right] .}
\end{aligned}
$$

The color image conversion algorithm from $R G B$ space to ACSM and its inverse conversion from ACSM to $R G B$ are presented by Algo-2 and Algo-3. The choice of color s pace (Color_Space), for the color image conversion process, depends on the dominant colors calculated using Algo-1. If the Color_Space="Model_l", then the color space $Y C_{c} C_{r}$ will be used, or the color space $Y C_{p} C_{g}$ that will be selected if Color_Space= "Model_2", whereas if Color_Space="Model_3", then the color space $Y C_{y} C_{b}$ will be used. The color image conversion process from $R G B$ Image to $A C S M_{-}$Image is done in the last line of the algorithm. This conversion process is carried out pixel by pixel. The Algo-3 is used for the inverse color conversion process from $A C S M_{-}$Image to $R G B$ _Image. 
Algo-2. RGB Image to ACSM Image conversion algorithm

\begin{tabular}{|c|c|c|c|c|}
\hline \multicolumn{4}{|c|}{$\begin{array}{l}\text { Input : RGB_Image, Color_Space } \\
\text { Output : } A C S M_{-} \text {Image }\end{array}$} & \multirow{5}{*}{$\% \%$ Color model 1} \\
\hline 1. & if Color Spāce & $=" \mathrm{Mo}$ & del 1" & \\
\hline \multirow[t]{3}{*}{2.} & $A C S M=[0.50$ & 0.25 & 0.25 & \\
\hline & 0.00 & 0.50 & -0.50 & \\
\hline & 0.50 & -0.25 & $-0.25]$ & \\
\hline 3. & else if Color_ $S_{I}$ & ace $=$ & "Model_2" & $\% \%$ Color model 2 \\
\hline \multirow{3}{*}{4} & $A C S M=[0.25$ & 0.50 & 0.25 & \\
\hline & 0.50 & 0.00 & -0.50 & \\
\hline & -0.25 & 0.50 & $-0.25]$ & \\
\hline \multicolumn{5}{|c|}{ 5. else } \\
\hline \multirow[t]{3}{*}{6.} & $A C S M=[0.25$ & 0.25 & 0.50 & $\% \%$ Color model 3 \\
\hline & 0.50 & -0.50 & 0.00 & \\
\hline & -0.25 & -0.25 & $0.50]$ & \\
\hline \multicolumn{5}{|c|}{ 7. end if } \\
\hline \multicolumn{5}{|c|}{ 8. $A C S M$ Image $=A C S M * R G B_{\text {IImage }}$} \\
\hline
\end{tabular}

Algo-3. ACSM_Image to RGB_Image conversion algorithm

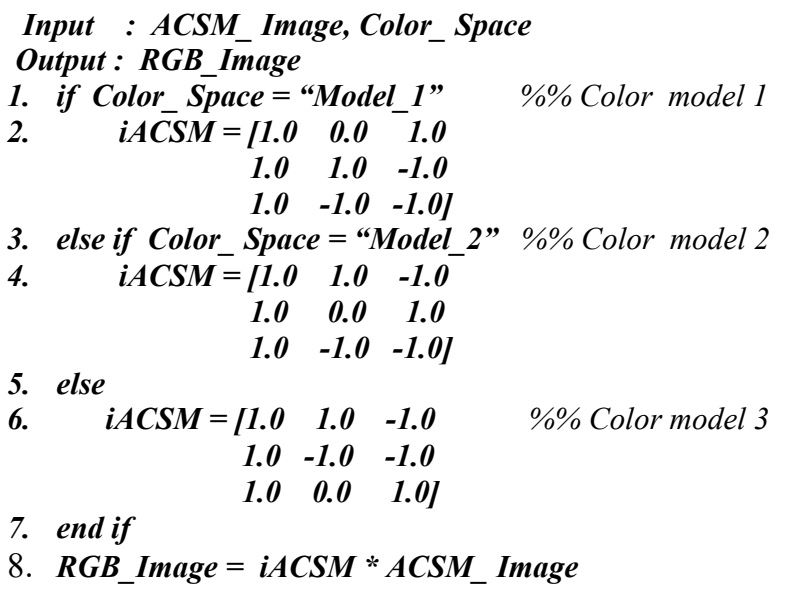

\section{Results and discussions}

The proposed dominant color analysis and ACSM algorithms have been integrated into the JPEG lossy image compression algorithm. Besides that, we also implemented the ACSM algorithm using $Y C_{g} C_{o}$-R color space family $\left(Y U V_{1}, Y U V_{2}\right.$ and $\left.Y U V_{3}\right)$. Both were tested using sixty images from $[17,18,19,20,21]$. The experimental results of the first twelve images are given in table 3 and the next forty-eight images are shown in tables $4-5$. In table 3 , there are eleven of the twelve images with the highest $\mathrm{CR}$ value offered by the $\mathrm{ACSM}-Y C_{o} C_{g}$ color space family (last column), while the ACSM- $Y C_{g} C_{o}-\mathrm{R}$ family only produces one image with the highest $\mathrm{CR}$ value (fourth column).

For Lena image, the adaptive color algorithm automatically selects and uses model- $1 Y C_{c} C_{r}$ color space, and obtained $\mathrm{CR}$ of $10.34 \%$ better than $Y C_{b} C_{r}$. Color space $\mathrm{YUV}_{3}$ is also automatically selected when ACSM$Y C_{g} C_{o}-\mathrm{R}$ family is implemented. This color space is $4.362 \%$ lower than $Y C_{b} C_{r}$. Color space Model-1 is also selected for Roses and Ucid00295 images and their CR are better than $Y C_{b} C_{r}$ and ACSM- $Y C_{g} C_{o}$-R family. An increase in $\mathrm{CR}$ is also seen in Peppers, Frymire, Tulips, and Textile images, where the color space chosen is model-3 $Y C_{y} C_{b}$. Furthermore, for Baboon, Sails, Monarch, and Woman images, model-2 $Y C_{p} C_{g}$ color space is used, where the compression ratios results are also better than $Y C_{b} C_{r}$ and ACSM- $Y C_{g} C_{o}-\mathrm{R}$ family. The higher CR for Yellow_Orchid image is given by $Y U V_{3}$ of ACSM- $Y C_{g} C_{o}-\mathrm{R}$ family. Its compression ratio is $12.77 \%$ better than $Y C_{b} C_{r}$ and $2.607 \%$ better than the ACSM- $Y C_{o} C_{g}$ family.

Furthermore, in tables $4-5$, it can be observed that there are forty-one out of forty-eight images having the highest quality and compression ratio produced by the proposed ACSM- $Y C_{o} C_{g}$ family. $Y C_{b} C_{r}$ and ACSM$Y C_{g} C_{o}-\mathrm{R}$ family provide the highest quality and compression ratio of the other four and three images, respectively. On average, ACSM- $Y C_{o} C_{g}$ family can enhance the $\mathrm{CR}$ by $5,046 \%$ for the first 12 images, while for the next $48 \mathrm{im}-$ ages the $\mathrm{CR}$ and compression quality increase $4,555 \%$ and $0.303 \mathrm{~dB}$ comparatively to $Y C_{b} C_{r}$. Conversely, there was a decrease in $\mathrm{CR}$ of $0.420 \%$ for the first 12 images and a decrease in CR of $2.087 \%$ and compression quantity of $0.439 \mathrm{~dB}$ for the next 48 images, when ACSM$Y C_{g} C_{o}$-R family was used.

Table 3. Compression ratio of $Y C_{b} C_{r}, Y C_{o} C_{g}$ and adaptive color space: $Y C_{c} C_{r}, Y C_{p} C_{g}, Y C_{y} C_{b}$

\begin{tabular}{|c|c|c|c|c|}
\hline \multirow{3}{*}{$\begin{array}{c}\text { File Image } \\
\text { (png) }\end{array}$} & \multirow{3}{*}{$\begin{array}{c}\text { Quality } \\
\text { PSNR } \\
\text { (dB) }\end{array}$} & \multicolumn{3}{|c|}{$\begin{array}{c}\text { Compression Ratio (CR) Using Color } \\
\text { Space: }\end{array}$} \\
\hline & & \multirow[b]{2}{*}{$Y C_{b} C_{r}$} & \multicolumn{2}{|c|}{ ACSM appled to: } \\
\hline & & & $\begin{array}{c}Y U V_{1}, Y U V_{2} \\
Y U V_{3}\end{array}$ & $\begin{array}{c}Y C_{c} C_{r}, Y C_{p} C_{g} \\
Y C_{y} C_{b}\end{array}$ \\
\hline Lena & 36.117 & 9.490 & $9.076\left(Y U V_{3}\right)$ & $10.471\left(Y C_{c} C_{r}\right)$ \\
\hline Baboon & 32.805 & 3.554 & $3.543\left(Y U V_{l}\right)$ & 3.798 $\left(Y C_{p} C_{g}\right)$ \\
\hline Peppers & 34.057 & 6.161 & $6.419\left(Y U V_{2}\right)$ & 6.695 $\left(Y C_{y} C_{b}\right)$ \\
\hline Frymire & 34.227 & 3.696 & $3.597\left(Y U V_{3}\right)$ & $3.771\left(Y C_{y} C_{b}\right)$ \\
\hline Roses & 46.776 & 19.96 & $19.340\left(Y U V_{3}\right)$ & $20.145\left(Y C_{c} C_{r}\right)$ \\
\hline Tulips & 33.764 & 3.784 & $3.669\left(Y U V_{2}\right)$ & $3.926\left(Y C_{y} C_{b}\right)$ \\
\hline Sails & 37.456 & 7.451 & $7.220\left(Y U V_{l}\right)$ & $7.750\left(Y C_{p} C_{g}\right)$ \\
\hline Monarch & 39.788 & 12.288 & $11.834\left(Y U V_{l}\right)$ & $12.553\left(Y C_{p} C_{g}\right)$ \\
\hline Textile & 36.838 & 5.442 & $5.439\left(Y U V_{2}\right)$ & $\mathbf{5 . 6 5 0}\left(Y C_{y} C_{b}\right)$ \\
\hline Woman & 38.011 & 10.156 & $9.062\left(Y U V_{3}\right)$ & $10.442\left(Y C_{p} C_{g}\right)$ \\
\hline Yellow_Orc & 41.050 & 21.398 & $24.131\left(Y U V_{2}\right)$ & $23.518\left(Y C_{y} C_{b}\right)$ \\
\hline Ucid00295 & 36.614 & 7.642 & $7.228\left(Y U V_{l}\right)$ & $7.908\left(Y C_{c} C_{r}\right)$ \\
\hline \multicolumn{2}{|c|}{ CR Average } & 9.252 & 9.213 & 9.719 \\
\hline \multicolumn{3}{|c|}{ Note: $\uparrow$ Increase $\downarrow$ Decrease } & $\downarrow 0.420 \%$ & $\uparrow 5.046 \%$ \\
\hline
\end{tabular}

Furthermore, the adaptive color space performance test is performed using seven Photoshop's quantization matrices from the high $\mathrm{Q}_{12}$ to the low $\mathrm{Q}_{6}$ compression quality (i.e. $\left.\mathrm{Q}_{12}, \mathrm{Q}_{11}, \mathrm{Q}_{10}, \mathrm{Q}_{9}, \mathrm{Q}_{8}, \mathrm{Q}_{7}, \mathrm{Q}_{6}\right)[22,30]$. Tables $6-8$ show the quality (PSNR) and compression ratio for Lena, Baboon and Textile images and graphically show by the curves in Figs. 4-6. The adaptive color space curves for the three images are above the $Y C_{b} C_{r}$ color space curve. This shows that the proposed adaptive model has a better performance. 
Table 4. Compression ratio of $Y C_{b} C_{r}, Y C_{o} C_{g}, A C S M-Y C_{g} C_{o}-R\left(Y U V_{l}, Y U V_{2}, Y U V_{3}\right)$ and $A C S M-Y C_{o} C_{g}\left(Y C_{c} C_{r}, Y C_{p} C_{g}, Y C_{y} C_{b}\right)$

\begin{tabular}{|c|c|c|c|c|c|c|c|c|}
\hline \multirow{3}{*}{ Image file name } & \multirow{2}{*}{\multicolumn{2}{|c|}{$\mathrm{YC}_{\mathrm{b}} \mathrm{C}_{\mathrm{r}}$}} & \multirow{3}{*}{$\frac{Y_{C_{0}} \mathbf{C}_{g}}{C R}$} & \multirow{3}{*}{$\begin{array}{c}\mathbf{Y U V}_{1} \\
\mathbf{Y C}_{\mathrm{g}} \mathrm{C}_{\mathbf{0}}-\mathrm{R} \\
\mathrm{CR}\end{array}$} & \multirow{3}{*}{$\begin{array}{c}\mathbf{Y U V} \mathbf{V}_{\mathbf{2}} \\
\mathrm{CR}\end{array}$} & \multirow{3}{*}{$\frac{\mathbf{Y U V}_{\mathbf{2}}}{\mathrm{CR}}$} & \multicolumn{2}{|c|}{ ACSM: $Y U V_{l}, \mathrm{ACSM}: Y C_{c} C_{r}$} \\
\hline & & & & & & & \multirow{2}{*}{\begin{tabular}{|c|}
$\boldsymbol{Y U U} \boldsymbol{V}_{\mathbf{2}}, \boldsymbol{Y U} U \boldsymbol{V}_{\mathbf{3}}$ \\
$\mathrm{CR}$
\end{tabular}} & \multirow{2}{*}{$\frac{Y C_{p} C_{g}, Y C_{y} C_{b}}{\text { CR }}$} \\
\hline & PSNR (dB) & $\mathrm{CR}$ & & & & & & \\
\hline 5 colors_544×544 & 38.611 & 7.468 & 7.569 & 7.309 & 7.322 & 7.385 & 7.385 & 7.583 \\
\hline 408px-Killersudoku_color & 41.071 & 11.429 & 11.205 & 10.756 & 10.756 & 10.868 & 10.868 & 11.730 \\
\hline 73755 & 39.277 & 15.136 & 15.140 & 14.639 & 14.436 & 14.855 & 14.855 & 15.297 \\
\hline 3975590069_7d5e05207e_o & 45.767 & 37.588 & 39.581 & 38.840 & 39.484 & 40.538 & 40.538 & 39.638 \\
\hline article-0-0B9771B5000005... & 44.027 & 17.167 & 17.509 & 16.092 & 16.354 & 16.093 & 16.354 & 17.509 \\
\hline Best-Science-Images-2007-I... & 47.342 & 20.269 & 18.591 & 18.353 & 17.759 & 18.346 & 18.353 & 19.147 \\
\hline Best-Science-Images-2007-II... & 40.302 & 10.604 & 10.245 & 11.039 & 10.268 & 10.883 & 11.039 & 10.775 \\
\hline bike_orig_1280x1600 & 36.740 & 8.383 & 8.785 & 7.435 & 7.754 & 7.683 & 7.754 & 8.785 \\
\hline butterfly_3 & 45.780 & 19.965 & 19.933 & 19.184 & 19.442 & 19.399 & 19.442 & 20.062 \\
\hline cafe_orig_1280x1600 & 34.084 & 4.365 & 4.598 & 4.200 & 4.239 & 4.154 & 4.239 & 4.598 \\
\hline computer-science-ultimate & 38.722 & 8.3158 & 7.658 & 7.289 & 7.634 & 7.187 & 7.634 & 8.095 \\
\hline dc7b126a-20f9-4569-bfd4-ce... & 39.482 & 9.139 & 9.489 & 8.671 & 8.541 & 8.564 & 8.671 & 9.489 \\
\hline F1_large & 40.337 & 10.828 & 10.718 & 10.446 & 10.647 & 10.740 & 10.740 & 11.056 \\
\hline glas_coloured_6 & 41.043 & 17.102 & 17.389 & 17.084 & 17.344 & 17.020 & 17.344 & 17.617 \\
\hline p-radiologist-art1_1467422c & 37.968 & 6.709 & 7.076 & 7.125 & 6.810 & 6.797 & 7.125 & 7.076 \\
\hline p01_orig_1280x1600 & 39.844 & 11.145 & 10.604 & 10.098 & 10.793 & 10.495 & 10.793 & 11.020 \\
\hline p06_orig_1280x1600 & 39.026 & 12.194 & 12.303 & 11.505 & 11.373 & 11.510 & 11.510 & 12.303 \\
\hline p30_orig_1280x1600 & 36.627 & 9.296 & 8.581 & 7.863 & 8.490 & 8.031 & 8.490 & 9.236 \\
\hline Screen-Searchmetri_968×576 & 40.886 & 14.033 & 15.431 & 14.640 & 13.719 & 13.979 & 14.640 & 15.431 \\
\hline Spectrscopic_mapping_speeds. & 44.479 & 11.834 & 11.717 & 11.251 & 11.195 & 11.177 & 11.251 & 11.878 \\
\hline stadtplan-museum-o_880×600 & 35.788 & 5.641 & 5.750 & 5.228 & 5.319 & 5.108 & 5.319 & 5.776 \\
\hline stewart_tartan_2 & 39.212 & 7.33 & 7.373 & 6.689 & 6.842 & 6.881 & 6.881 & 7.373 \\
\hline surface_2 & 42.713 & 20.925 & 22.584 & 22.143 & 21.481 & 21.555 & 21.481 & 22.584 \\
\hline ucid00032 & 36.554 & 7.995 & 8.564 & 7.537 & 7.049 & 7.213 & 7.537 & 8.564 \\
\hline ucid00041 & 37.931 & 11.579 & 12.815 & 11.217 & 10.565 & 10.399 & 11.217 & 12.815 \\
\hline ucid00045 & 37.645 & 11.031 & 12.140 & 10.323 & 9.691 & 9.432 & 10.323 & 12.140 \\
\hline ucid00059 & 37.414 & 10.691 & 11.495 & 9.417 & 9.276 & 8.954 & 9.417 & 11.495 \\
\hline ucid00066 & 38.694 & 14.181 & 15.383 & 13.215 & 12.588 & 12.126 & 13.215 & 15.383 \\
\hline ucid00110 & 33.792 & 5.597 & 5.962 & 5.265 & 5.013 & 4.889 & 5.265 & 5.962 \\
\hline ucid00262 & 37.118 & 8.702 & 8.710 & 8.009 & 7.872 & 8.522 & 8.522 & 9.235 \\
\hline ucid00275 & 35.955 & 6.611 & 6.876 & 6.317 & 6.039 & 6.438 & 6.438 & 6.905 \\
\hline ucid00295 & 36.614 & 7.642 & 7.908 & 7.228 & 7.086 & 7.174 & 7.228 & 7.908 \\
\hline ucid00302 & 37.754 & 9.697 & 10.531 & 9.709 & 9.148 & 9.446 & 9.446 & 10.531 \\
\hline ucid00317 & 38.474 & 15.023 & 16.341 & 14.326 & 13.878 & 13.723 & 14.326 & 16.341 \\
\hline ucid00368 & 35.466 & 5.635 & 6.255 & 5.798 & 5.726 & 5.446 & 5.798 & 6.255 \\
\hline ucid00410 & 34.695 & 4.793 & 5.008 & 4.673 & 4.534 & 4.545 & 4.673 & 5.066 \\
\hline ucid00456 & 36.374 & 6.892 & 7.193 & 6.639 & 6.431 & 6.565 & 6.639 & 7.193 \\
\hline ucid00457 & 39.619 & 14.076 & 14.367 & 12.804 & 12.447 & 12.900 & 12.900 & 14.367 \\
\hline ucid00489 & 37.097 & 8.831 & 8.946 & 8.043 & 7.881 & 8.041 & 8.043 & 8.946 \\
\hline ucid00514 & 34.844 & 5.053 & 5.055 & 4.650 & 4.608 & 4.744 & 4.744 & 5.172 \\
\hline ucid00648 & 36.711 & 8.827 & 9.440 & 8.443 & 7.982 & 8.197 & 8.443 & 9.440 \\
\hline ucid00687 & 34.979 & 5.153 & 5.444 & 5.027 & 4.812 & 5.016 & 5.027 & 5.444 \\
\hline ucid00758 & 36.705 & 8.854 & 9.563 & 8.618 & 8.340 & 8.100 & 8.618 & 9.563 \\
\hline ucid00804 & 39.598 & 16.251 & 19.805 & 19.041 & 15.760 & 15.950 & 19.041 & 19.805 \\
\hline ucid00811 & 38.649 & 12.234 & 12.820 & 11.524 & 10.998 & 11.412 & 11.524 & 12.820 \\
\hline ucid00860 & 37.882 & 11.197 & 11.251 & 10.604 & 10.467 & 10.272 & 10.604 & 11.251 \\
\hline ucid00884 & 35.413 & 6.021 & 6.439 & 5.731 & 5.397 & 5.619 & 5.731 & 6.439 \\
\hline WFCAM_JHK_colour-comp... & 42.822 & 14.177 & 14.819 & 14.718 & 15.038 & 14.194 & 15.038 & 14.819 \\
\hline \multicolumn{2}{|c|}{ CR average: } & 11.117 & 11.520 & 10.766 & 10.555 & 10.595 & 10.885 & 11.623 \\
\hline \multicolumn{3}{|c|}{ Note: $\uparrow$ Increase $\downarrow$ Decrease } & $\uparrow 3.626 \%$ & $\downarrow 3.158 \%$ & $\downarrow 5.056 \%$ & $\downarrow 4.693 \%$ & $\downarrow 2.087 \%$ & $\uparrow 4.555 \%$ \\
\hline
\end{tabular}


Table 5. Compression quality of $Y C_{b} C_{r}, Y C_{o} C_{g}, A C S M-Y C_{g} C_{o}-R\left(Y U V_{l}, Y U V_{2}, Y U V_{3}\right)$ and $A C S M-Y C_{o} C_{g}\left(Y C_{c} C_{r}, Y C_{p} C_{g}, Y C_{y} C_{b}\right)$

\begin{tabular}{|c|c|c|c|c|c|c|c|c|}
\hline \multirow[t]{2}{*}{ Image file name } & \multicolumn{2}{|c|}{$Y C_{b} C_{r}$} & \multirow{2}{*}{$\begin{array}{c}\boldsymbol{Y} \boldsymbol{C}_{\boldsymbol{g}} \boldsymbol{C}_{\boldsymbol{0}} \\
\mathrm{PSNR}(\mathrm{dB})\end{array}$} & \multirow{2}{*}{\begin{tabular}{|c|}
$\boldsymbol{Y U} \boldsymbol{V}_{\boldsymbol{1}}$ \\
PSNR (dB)
\end{tabular}} & \multirow{2}{*}{\begin{tabular}{|c|}
$\boldsymbol{Y} \boldsymbol{C}_{\boldsymbol{g}} \boldsymbol{C}_{\boldsymbol{0}}-\boldsymbol{R}$ \\
$\boldsymbol{Y U} \boldsymbol{V}_{\mathbf{2}}$ \\
$\mathrm{PSNR}(\mathrm{dB})$
\end{tabular}} & \multirow{2}{*}{$\begin{array}{c}\boldsymbol{Y} \boldsymbol{U} \boldsymbol{V}_{\mathbf{3}} \\
\text { PSNR (dB) }\end{array}$} & \multirow{2}{*}{\begin{tabular}{|c}
$\begin{array}{c}\text { ACSM: } \boldsymbol{Y} \boldsymbol{U} \boldsymbol{V}_{\boldsymbol{l}}, \\
\boldsymbol{Y} \boldsymbol{U} \boldsymbol{V}_{\mathbf{2}}, \boldsymbol{Y} \boldsymbol{U} \boldsymbol{V}_{\mathbf{3}}\end{array}$ \\
PSNR (dB)
\end{tabular}} & \multirow{2}{*}{$\begin{array}{c}\mathrm{ACSM}: \boldsymbol{Y} \boldsymbol{C}_{c} \boldsymbol{C}_{\boldsymbol{r}}, \\
\boldsymbol{Y} \boldsymbol{C}_{\boldsymbol{p}} \boldsymbol{C}_{\boldsymbol{g}}, \boldsymbol{Y} \boldsymbol{C}_{\boldsymbol{y}} \boldsymbol{C}_{\boldsymbol{b}} \\
\mathrm{PSNR}(\mathrm{dB})\end{array}$} \\
\hline & $\mathrm{CR}$ & $\operatorname{PSNR}(\mathrm{dB})$ & & & & & & \\
\hline 5 colors_544×544 & 7.468 & 38.611 & 38.875 & 38.084 & 38.131 & 38.329 & 38.329 & 38.944 \\
\hline 408px-Killersudoku_color & 11.429 & 41.071 & 40.697 & 39.511 & 39.511 & 39.857 & 39.857 & 41.530 \\
\hline 73755 & 15.136 & 39.277 & 39.278 & 39.165 & 39.112 & 39.225 & 39.225 & 39.308 \\
\hline 3975590069_7d5e05207e_o & 37.588 & 45.767 & 45.927 & 45.859 & 45.918 & 45.961 & 45.961 & 45.927 \\
\hline article-0-0B9771B5000005... & 17.167 & 44.027 & 44.338 & 42.735 & 43.074 & 42.736 & 43.074 & 44.344 \\
\hline Best-Science-Images-2007-I... & 20.269 & 47.342 & 41.826 & 43.761 & 42.977 & 43.719 & 43.761 & 45.231 \\
\hline Best-Science-Images-2007-II... & 10.604 & 40.302 & 39.729 & 40.836 & 39.814 & 40.673 & 40.836 & 40.579 \\
\hline bike_orig_1280×1600 & 8.383 & 36.740 & 37.053 & 35.866 & 36.123 & 36.125 & 36.125 & 37.053 \\
\hline butterfly_3 & 19.965 & 45.780 & 45.762 & 45.330 & 45.465 & 45.452 & 45.465 & 45.833 \\
\hline cafe_orig_1280×1600 & 4.365 & 34.084 & 34.559 & 33.592 & 33.716 & 33.439 & 33.716 & 34.559 \\
\hline computer-science-ultimate & 8.3158 & 38.722 & 36.989 & 36.445 & 37.058 & 35.884 & 37.058 & 38.254 \\
\hline dc7b126a-20f9-4569-bfd4-ce... & 9.139 & 39.482 & 39.982 & 38.640 & 38.386 & 38.456 & 38.640 & 39.982 \\
\hline F1_large & 10.828 & 40.337 & 40.210 & 39.788 & 40.086 & 40.216 & 40.216 & 40.581 \\
\hline glas_coloured_6 & 17.102 & 41.043 & 41.097 & 41.039 & 41.091 & 41.024 & 41.091 & 41.144 \\
\hline p-radiologist-art1_1467422c & 6.709 & 37.968 & 38.448 & 38.472 & 38.141 & 38.128 & 38.128 & 38.448 \\
\hline p01_orig_1280×1600 & 11.145 & 39.844 & 39.486 & 39.041 & 39.581 & 39.361 & 39.581 & 39.760 \\
\hline p06_orig_1280 $\times 1600$ & 12.194 & 39.026 & 39.090 & 38.530 & 38.443 & 38.526 & 38.530 & 39.090 \\
\hline p30_orig_1280×1600 & 9.296 & 36.627 & 36.132 & 35.202 & 35.761 & 35.423 & 35.761 & 36.583 \\
\hline Screen-Searchmetri_968×576 & 14.033 & 40.886 & 42.320 & 41.709 & 40.424 & 40.809 & 41.709 & 42.320 \\
\hline Spectrscopic_mapping_speed... & 11.834 & 44.479 & 44.400 & 43.772 & 43.592 & 43.617 & 43.772 & 44.507 \\
\hline stadtplan-museum-o_880×600 & 5.641 & 35.788 & 36.008 & 34.766 & 34.961 & 34.437 & 34.961 & 36.062 \\
\hline stewart_tartan_2 & 7.33 & 39.212 & 39.350 & 36.897 & 37.722 & 37.746 & 37.746 & 39.350 \\
\hline surface_2 & 20.925 & 42.713 & 42.987 & 42.930 & 42.812 & 42.827 & 42.930 & 42.987 \\
\hline ucid00032 & 7.995 & 36.554 & 37.073 & 36.052 & 35.464 & 35.636 & 36.052 & 37.073 \\
\hline ucid00041 & 11.579 & 37.931 & 38.482 & 37.756 & 37.446 & 37.321 & 37.756 & 38.482 \\
\hline ucid00045 & 11.031 & 37.645 & 38.137 & 37.302 & 36.995 & 36.791 & 37.302 & 38.137 \\
\hline ucid00059 & 10.691 & 37.414 & 37.810 & 36.621 & 36.649 & 36.387 & 36.649 & 37.810 \\
\hline ucid00066 & 14.181 & 38.694 & 39.014 & 38.419 & 38.269 & 38.069 & 38.419 & 39.014 \\
\hline ucid00110 & 5.597 & 33.792 & 34.105 & 33.182 & 32.668 & 32.334 & 33.182 & 34.105 \\
\hline ucid00262 & 8.702 & 37.118 & 37.125 & 36.379 & 36.243 & 36.949 & 36.949 & 37.547 \\
\hline ucid00275 & 6.611 & 35.955 & 36.279 & 35.530 & 35.052 & 35.715 & 35.715 & 36.535 \\
\hline ucid00295 & 7.642 & 36.614 & 36.919 & 36.041 & 35.861 & 35.995 & 36.041 & 36.921 \\
\hline ucid00302 & 9.697 & 37.754 & 38.344 & 37.763 & 37.287 & 37.555 & 37.763 & 38.344 \\
\hline ucid00317 & 15.023 & 38.474 & 38.764 & 38.296 & 38.197 & 38.131 & 38.296 & 38.764 \\
\hline ucid00368 & 5.635 & 35.466 & 36.443 & 35.783 & 35.642 & 35.081 & 35.783 & 36.443 \\
\hline ucid00410 & 4.793 & 34.695 & 35.170 & 34.358 & 33.859 & 33.975 & 33.975 & 35.265 \\
\hline ucid00456 & 6.892 & 36.374 & 36.770 & 35.979 & 35.666 & 35.879 & 35.979 & 36.770 \\
\hline ucid00457 & 14.076 & 39.619 & 39.765 & 38.984 & 38.825 & 39.045 & 39.045 & 39.765 \\
\hline ucid00489 & 8.831 & 37.097 & 37.195 & 36.332 & 36.093 & 36.318 & 36.332 & 37.195 \\
\hline ucid00514 & 5.053 & 34.844 & 34.847 & 33.866 & 33.750 & 34.113 & 34.113 & 35.050 \\
\hline ucid00648 & 8.827 & 36.711 & 37.176 & 36.421 & 36.000 & 36.212 & 36.421 & 37.176 \\
\hline ucid00687 & 5.153 & 34.979 & 35.527 & 34.682 & 34.132 & 34.651 & 34.651 & 35.527 \\
\hline ucid00758 & 8.854 & 36.705 & 37.260 & 36.514 & 36.294 & 36.068 & 36.514 & 37.260 \\
\hline ucid00804 & 16.251 & 39.598 & 40.755 & 40.465 & 39.417 & 39.487 & 39.487 & 40.755 \\
\hline ucid00811 & 12.234 & 38.649 & 38.962 & 38.231 & 37.919 & 38.178 & 38.231 & 38.962 \\
\hline ucid00860 & 11.197 & 37.882 & 37.920 & 37.471 & 37.382 & 37.249 & 37.471 & 37.920 \\
\hline ucid00884 & 6.021 & 35.413 & 36.007 & 34.897 & 34.266 & 34.707 & 34.897 & 36.007 \\
\hline WFCAM_JHK_colour-comp... & 14.177 & 42.822 & 43.251 & 43.290 & 43.371 & 42.836 & 43.371 & 43.251 \\
\hline \multicolumn{2}{|l|}{ PSNR average $(\mathrm{dB})$ : } & 38.707 & 38.826 & 38.179 & 38.013 & 38.055 & 38.268 & 39.009 \\
\hline \multicolumn{3}{|c|}{ Note: $\uparrow$ Increase $\downarrow$ Decrease $(\mathrm{dB})$ : } & $\uparrow 0.119$ & $\downarrow 0.528$ & $\downarrow 0.693$ & $\downarrow 0.652$ & $\downarrow 0.439$ & $\uparrow 0.303$ \\
\hline
\end{tabular}


Table 6. PSNR and $C R$ of $Y C_{b} C_{r}$ and ACSM for Lena image

\begin{tabular}{|c|c|c|c|c|}
\hline \multirow{2}{*}{$\begin{array}{l}\text { Matrix } \\
\text { Quality }\end{array}$} & \multicolumn{2}{|c|}{$Y C_{b} C_{r}$} & \multicolumn{2}{|c|}{$\begin{array}{c}A C S M: Y C_{c} C_{r} \\
Y C_{p} C_{g}, Y C_{y} C_{b}\end{array}$} \\
\hline & $\operatorname{PSNR}(\mathrm{dB})$ & CR & PSNR (dB) & CR \\
\hline $\mathrm{Q}_{6}$ & 34.545 & 13.027 & 34.691 & 13.719 \\
\hline $\mathrm{Q}_{7}$ & 35.365 & 11.504 & 35.509 & 12.072 \\
\hline $\mathrm{Q}_{8}$ & 35.396 & 11.170 & 35.550 & 11.757 \\
\hline $\mathrm{Q}_{9}$ & 36.117 & 9.490 & 36.275 & 9.957 \\
\hline $\mathrm{Q}_{10}$ & 36.934 & 7.457 & 37.105 & 7.789 \\
\hline $\mathrm{Q}_{11}$ & 39.111 & 4.512 & 39.386 & 4.621 \\
\hline $\mathrm{Q}_{12}$ & 46.143 & 2.401 & 46.564 & 2.429 \\
\hline
\end{tabular}

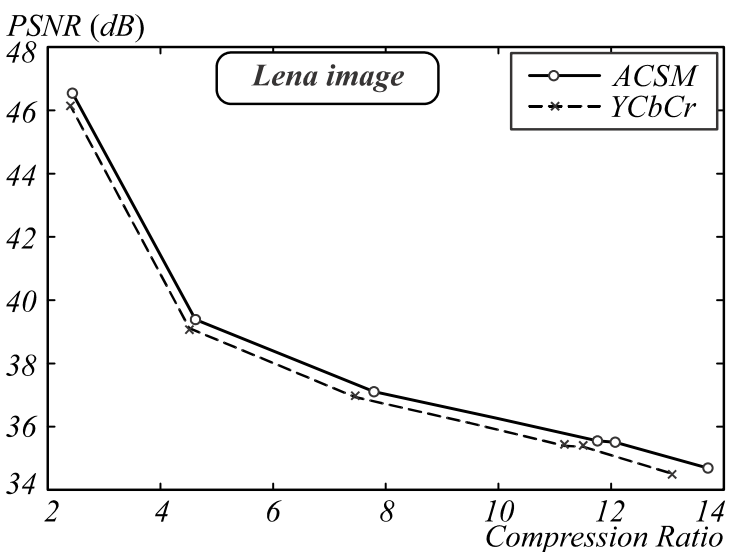

Fig. 4. PSNR vs CR curves of $Y C_{b} C_{r}$ and ACSM for Lena image

Table 8. PSNR and CR of $Y C_{b} C_{r}$ and ACSM for Textile image

\begin{tabular}{|c|c|c|c|c|}
\hline \multirow{2}{*}{$\begin{array}{c}\text { Matrix } \\
\text { Quality }\end{array}$} & \multicolumn{2}{|c|}{$\boldsymbol{Y C}_{\boldsymbol{b}} \boldsymbol{C}_{\boldsymbol{r}}$} & \multicolumn{2}{c|}{$\begin{array}{c}\text { ACSM: } \boldsymbol{Y} \boldsymbol{Y C}_{\boldsymbol{c}} \boldsymbol{C}_{\boldsymbol{r}}, \\
\boldsymbol{Y C}_{\boldsymbol{p}} \boldsymbol{C}_{\boldsymbol{g}}, \boldsymbol{Y} \boldsymbol{C}_{\boldsymbol{y}} \boldsymbol{C}_{\boldsymbol{b}}\end{array}$} \\
\cline { 2 - 5 } & PSNR (dB) & $\mathrm{CR}$ & $\mathrm{PSNR}(\mathrm{dB})$ & $\mathrm{CR}$ \\
\hline $\mathrm{Q}_{6}$ & 33.246 & 7.048 & 33.461 & 7.168 \\
\hline $\mathrm{Q}_{7}$ & 35.442 & 6.208 & 35.622 & 6.303 \\
\hline $\mathrm{Q}_{8}$ & 34.961 & 6.236 & 35.219 & 6.324 \\
\hline $\mathrm{Q}_{9}$ & 36.838 & 5.442 & 37.140 & 5.537 \\
\hline $\mathrm{Q}_{10}$ & 38.873 & 4.654 & 39.075 & 4.717 \\
\hline $\mathrm{Q}_{11}$ & 42.191 & 3.572 & 42.411 & 3.60 \\
\hline $\mathrm{Q}_{12}$ & 48.269 & 2.453 & 48.4971 & 2.426 \\
\hline
\end{tabular}

Besides its better performance, the implementation of the proposed adaptive color space in the form of an electronic circuit is very simple and only requires adders and subtractors. It is as simple as the electronic implementation of $Y C_{g} C_{o}-\mathrm{R}$ color space family [13]. Suppose each color data $R$, $G$ and $B$ of an image is encoded with eight bits, that is: $R=r_{7}, \ldots, r_{0} ; G=g_{7}, \ldots, g_{0}$; and $B=b_{7}, \ldots, b_{0}$. Arithmetic operations for these data are carried out in binary operations: addition, subtraction, and logic. The symbol "»1", is a onebit shift-right operation, used instead of multiply by 0.5 . For example, the Eq. (10) can be simplified as:

$$
\begin{aligned}
& Y=0.5 R+0.25 G+0.25 B \rightarrow Y=(R+((G+B) » 1)) » 1, \\
& \mathrm{C}_{\mathrm{c}}=0.5 \mathrm{G}-0.5 \mathrm{~B} \rightarrow \mathrm{C}_{\mathrm{c}}=(\mathrm{G}-\mathrm{B}) » 1,
\end{aligned}
$$

\begin{tabular}{|c|c|c|c|c|}
\hline \multirow{2}{*}{$\begin{array}{l}\text { Matrix } \\
\text { Quality }\end{array}$} & \multicolumn{2}{|c|}{$Y C_{b} C_{r}$} & \multicolumn{2}{|c|}{$\begin{array}{c}A C S M: Y C_{c} C_{r} \\
Y C_{p} C_{g}, Y C_{y} C_{b}\end{array}$} \\
\hline & $\operatorname{PSNR}(\mathrm{dB})$ & $\mathrm{CR}$ & PSNR (dB) & $\mathrm{CR}$ \\
\hline $\mathrm{Q}_{6}$ & 30.914 & 4.152 & 31.452 & 4.180 \\
\hline $\mathrm{Q}_{7}$ & 32.050 & 3.872 & 32.509 & 3.906 \\
\hline $\mathrm{Q}_{8}$ & 31.912 & 3.857 & 32.492 & 3.883 \\
\hline $\mathrm{Q}_{9}$ & 32.805 & 3.554 & 33.403 & 3.582 \\
\hline $\mathrm{Q}_{10}$ & 33.814 & 3.144 & 34.417 & 3.17 \\
\hline $\mathrm{Q}_{11}$ & 37.696 & 2.328 & 38.262 & 2.347 \\
\hline $\mathrm{Q}_{12}$ & 46.102 & 1.534 & 46.567 & 1.545 \\
\hline
\end{tabular}

Table 7. PSNR and $C R$ of $Y C_{b} C_{r}$ and $A C S M$ for Baboon image

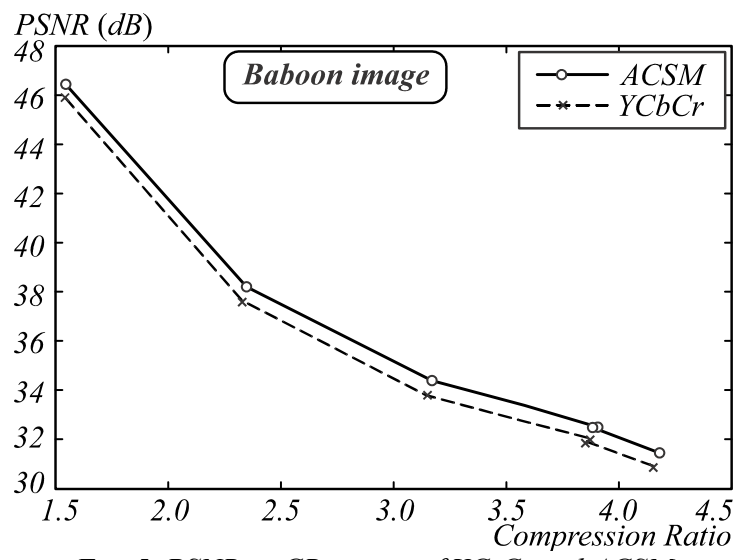

Fig. 5. PSNR vs CR curves of $Y C_{b} C_{r}$ and $A C S M$

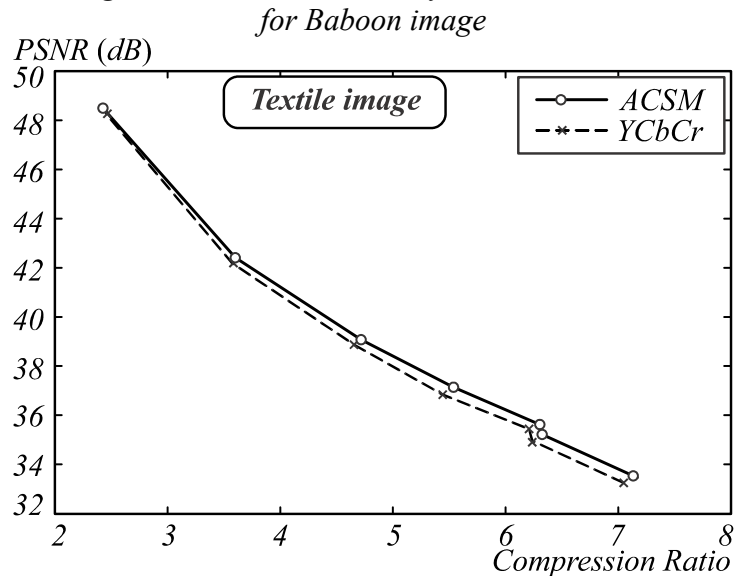

Fig. 6. PSNR vs CR curves of $Y C_{b} C_{r}$ and $A C S M$ for Textile image

$$
\mathrm{C}_{\mathrm{r}}=0.5 \mathrm{R}-0.25 \mathrm{G}-0.25 \mathrm{~B} \rightarrow \mathrm{C}_{\mathrm{r}}=(\mathrm{R}-((\mathrm{G}+\mathrm{B}) » 1)) » 1 .
$$

Referring to this simplification model, the electronic schematic of $R G B$ to $Y C_{c} C_{r}$ conversion can be created as shown in Fig. 7. This scheme only requires 2 adders and 2 subtractors. The luminance $Y$ component requires 10 bits, consisting of 8 bits for integer $\left(\mathrm{s}_{7}, \ldots, \mathrm{s}_{0}\right)$ value and 2 bits for fractional $\left(\mathrm{s}_{-1}, \mathrm{~s}_{-2}\right)$ value. While the cyan chrominance $C_{c}$ component needs 9 bits, that are 1 bit of borrow-out ( $\mathrm{s}_{7}$ as sign bit: " 0 " positive or " 1 " negative), 7 bits integer value $\left(\mathrm{s}_{6}, \ldots, \mathrm{s}_{0}\right)$, and 1 bit fractional $\left(\mathrm{s}_{-1}\right)$. Furthermore, the red chrominance $C_{r}$ component takes 10 bits consisting of 1 bit borrow-out ( $\mathrm{s}_{7}$ as sign bit), 7 bits inte ger $\left(\mathrm{s}_{6}, \ldots, \mathrm{s}_{0}\right)$, and 2 bits $\left(\mathrm{s}_{-1}, \mathrm{~s}_{-2}\right)$ fractional. 


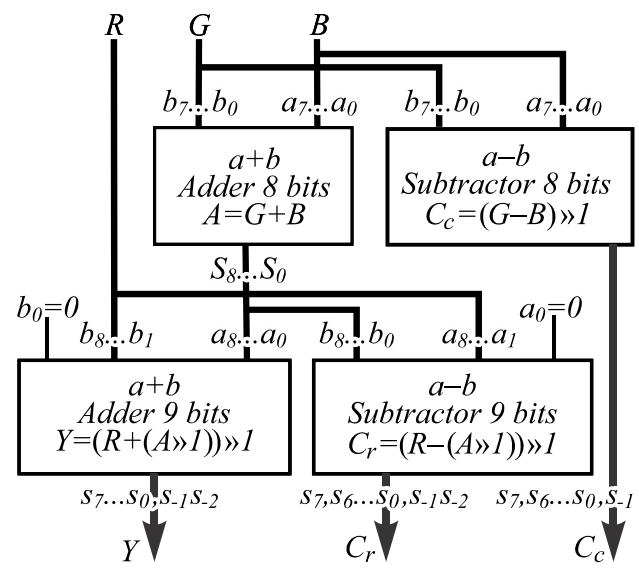

Fig. 7. Electronic schematic of $R G B$ to $Y C_{c} C_{r}$ color conversion

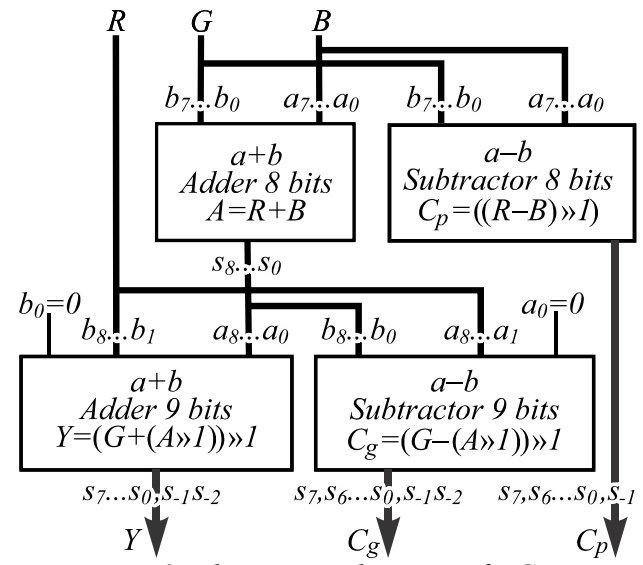

Fig. 9. Electronic schematic of $R G B$ to $Y C p C g$ color conversion

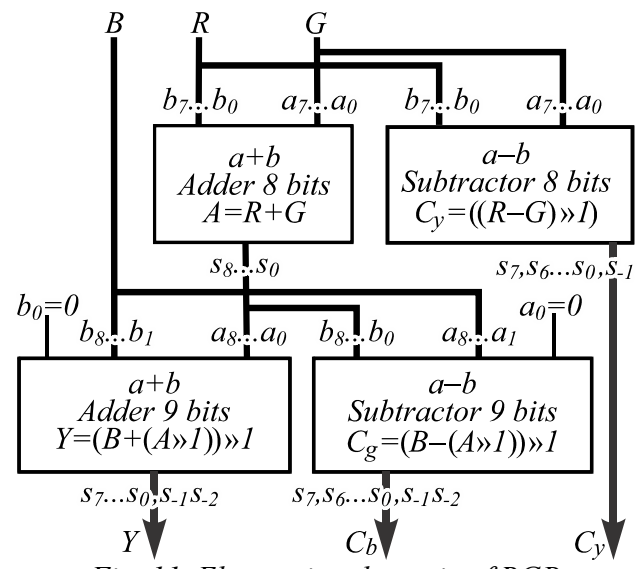

Fig. 11. Electronic schematic of $R G B$ to $\mathrm{YCy} \mathrm{Cb}$ color conversion

The inverse conversion process from $Y C_{c} C_{r}$ to $R G B$ in Eq. (11): $R=Y+C_{c}$,

$$
\begin{aligned}
& G=\left(Y-C_{r}\right)+C_{c}, \\
& B=\left(Y-C_{r}\right)-C_{c} .
\end{aligned}
$$

The electronic schematic of this equation is given by fig. 8. It can be seen that this inverse conversion only needs 2 adders and 2 subtractors.

In the same ways, the color model-2 from $R G B$ to $Y C_{p} C_{g}$ can be simplified as:

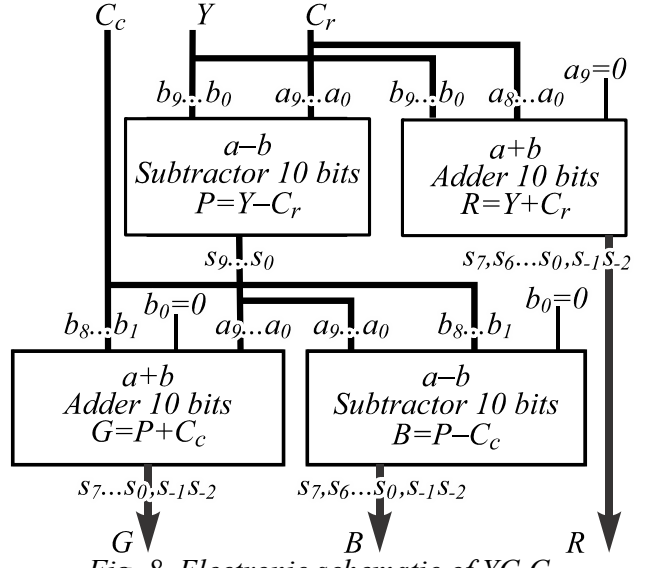

Fig. 8. Electronic schematic of $Y C_{c} C_{r}$ to $R G B$ color conversion

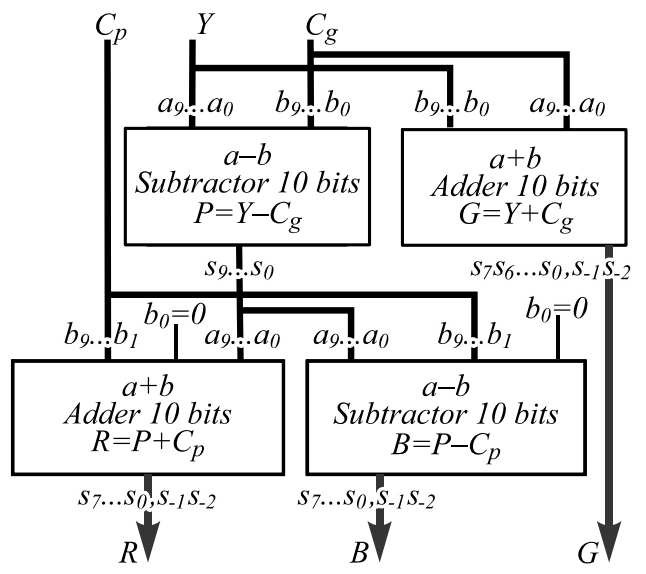

Fig. 10. Electronic schematic of $Y C_{p} C g$ to $R G B$ color conversion

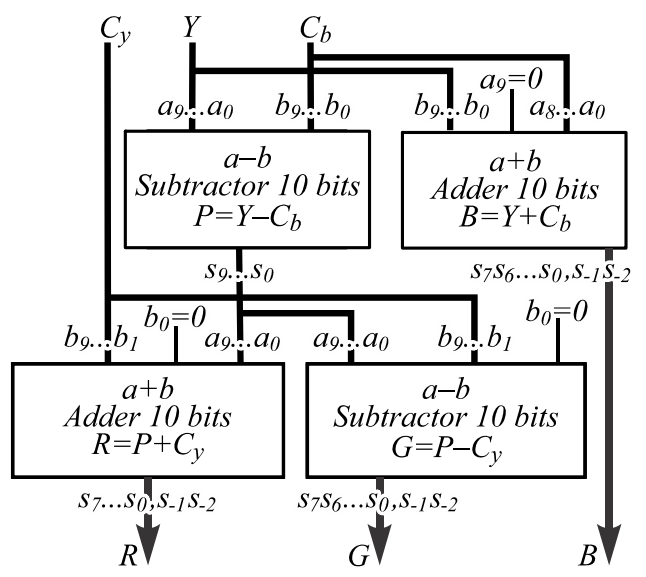

Fig. 12. Electronic schematic of $\mathrm{YCy} C b$ to $R G B$ color conversion

$$
\begin{aligned}
& Y=0.25 R+0.5 G+0.25 B \rightarrow Y=(G+((R+B) » 1)) » 1, \\
& \mathrm{C}_{\mathrm{p}}=0.5 \mathrm{R}-0.5 \mathrm{~B} \rightarrow \mathrm{C}_{\mathrm{p}}=(\mathrm{R}-\mathrm{B}) » 1, \\
& \mathrm{C}_{\mathrm{g}}=-0.25 \mathrm{R}+0.5 \mathrm{G}-0.25 \mathrm{~B} \rightarrow \mathrm{C}_{\mathrm{g}}=(\mathrm{G}-((\mathrm{R}+\mathrm{B}) » 1)) » 1 .
\end{aligned}
$$

and its inverse conversion from $Y C_{p} C_{g}$ to $R G B$ is:

$$
\begin{aligned}
& R=\left(Y-C_{g}\right)+C_{p}, \\
& G=\left(Y+C_{g}\right), \\
& B=\left(Y-C_{g}\right)-C_{p} .
\end{aligned}
$$


The electronic schematics diagrams of both $R G B$ to $Y C_{p} C_{g}$ and $Y C_{p} C g$ to $R G B$ colors conversion are sequentially presented in figs. $9-10$.

Similarly for the color model-3 $R G B$ to $Y C_{y} C_{b}$ is simplified as:

$$
\begin{aligned}
& \mathrm{Y}=0.25 \mathrm{R}+0.25 \mathrm{G}+0.5 \mathrm{~B} \rightarrow \mathrm{Y}=(\mathrm{B}+((\mathrm{R}+\mathrm{G}) » 1)) » 1, \\
& \mathrm{C}_{\mathrm{y}}=0.5 \mathrm{R}-0.5 \mathrm{G} \rightarrow \mathrm{C}_{\mathrm{y}}=(\mathrm{R}-\mathrm{G}) » 1, \\
& \mathrm{C}_{\mathrm{b}}=-0.25 \mathrm{R}-0.25 \mathrm{G}+0.5 \mathrm{~B} \rightarrow \mathrm{C}_{\mathrm{b}}=(\mathrm{B}-((\mathrm{R}+\mathrm{G}) » 1)) » 1 .
\end{aligned}
$$

and its inverse conversion from $Y C_{y} C_{b}$ to $R G B$ is:

$$
\begin{aligned}
& R=\left(Y-C_{b}\right)+C_{y}, \\
& G=\left(Y-C_{b}\right)-C_{y}, \\
& B=\left(Y+C_{b}\right) .
\end{aligned}
$$

The electronic schematics diagrams of both $R G B$ to $Y C_{y} C_{b}$ and $Y C_{y} C_{b}$ to $R G B$ colors conversion are sequentially presented in figs. $11-12$.

\section{Conclusion}

In this paper, three color spaces $Y C_{c} C_{r}, Y C_{p} C_{g}$, and $Y C_{y} C_{b}$ ( $Y C_{o} C_{g}$ color space family) have been developed that can be adapted according to the dominant colors contained in an image. The color analysis algorithm can calculate and determine the dominant colors in an image, and then automatically determines the appropriate color space to be applied in that image. The experimental results using sixty test images, which have varying colors, shapes, and textures, indicate that the proposed adaptive color spaces model provides improved performance of $3 \%$ to $10 \%$ better than other color spaces. Likewise, their electronic schematics require only two adders and two subtractors, both for forward and inverse conversions.

Our future research is to apply the dominant color analysis and adaptive color space model (ACSM) algorithm to the JPEG2000 image compression algorithm, and MPEG for video compression.

\section{Reference}

[1] Wallace GK. The JPEG still picture compression standard. IEEE Trans Consum Electron 1992; 38(1): 18-34

[2] Skodras A, Christopoulos C, Ebrahimi T. The JPEG 2000 still image compression standard. IEEE Signal Process Mag 2001; 18(5): 36-58.

[3] Saptariani T, Madenda S, Ernastuti, Silfianti W. Accelerating compression time of the standard JPEG by employing the quantized $\mathrm{YCbCr}$ color space algorithm. Int J Electr Comput Eng 2018; 8(6): 4343-4351.

[4] Rao KR, Hwang JJ. Techniques and standards for image, video and audio coding. Englewood Cliffs, NJ: PrenticeHall; 1996.

[5] Bhaskaran V, Konstantinides K. Image and video compression standards: Algorithms and applications. $2^{\text {nd }}$ ed. Norwell, MA: Kluwer; 1997.

[6] Progressive lossy to lossless core experiment with a region of interest: Results with the S, S+P, two-ten integer wavelets and with the difference coding method. ISO/IEC JTC1/SC29/WG1 N741, March 1998.

[7] Nadenau MJ, Reichel J. Opponent color, human vision and wavelets for image compression. Proc $7^{\text {th }}$ Color Imaging Conf 1999; 237-242.
[8] Taubman DS, Marcellin MW. JPEG2000 image compression fundamentals, standards and practice. Kluwer Academic Publishers; 2002.

[9] Pasteau F, Strauss C, Babel M, Déforges O, Bédat L. Improved colour decorrelation for lossless colour image compression using the LAR codec. European Signal Processing Conference (EUSIPCO’09) 2009; 1-4.

[10] Malvar HS, Sullivan GJ. Transform, scaling \& color space impact of professional extensions. ISO/IEC JTC1/SC29/WG11 and ITU-T SG16 Q.6 Document JVTH031 May 2003.

[11] Malvar HS, Sullivan GJ. YCoCg-R: A color space with $R G B$ reversibility and low dynamic range, joint video team (JVT) of ISO/IEC MPEG \& ITU-T VCEG, (ISO/IEC JTC1/SC29/WG11 and ITU-T SG16 Q.6), JVT PExt Ad Hoc Group Meeting 22-24 July 2003.

[12] Malvar HS, Sullivan GJ, Srinivasan S. Lifting-based reversible color transformations for image compression. Proc SPIE 2008; 7073: 707307.

[13] Strutz, T. Multiplierless reversible colour transforms and their automatic selection for image data compression. IEEE Trans Circuits Syst Video Technol 2013; 23(7): 12491259. DOI: 10.1109/TCSVT.2013.2242612.

[14] Marpe D, Kirchhoffer H, George V, Kauff P, Wiegand T. An adaptive color transform approach and its application in 4:4:4 video coding. Proc EUSIPCO 2006; 1-5.

[15] Strutz T, Leipnitz A. Adaptive colour-space selection in high efficiency video coding. $201725^{\text {th }}$ European Signal Processing Conference (EUSIPCO) 2017; 1534-1538. DOI: $10.23919 /$ EUSIPCO.2017.8081466.

[16] Schaefer G, Stich M. UCID - An uncompressed colour image database. Proc SPIE 2004; 5307: 472-480.

[17] Index of/strutz/Papers/Testimages. Source: 〈https://www1.hft-leipzig.de/strutz/Papers/Testimages/〉.

[18] Resources of ACSS. Source: 〈https://www1.hftleipzig.de/strutz/Papers/ACSS-resources//.

[19] Index of/strutz/Papers/Testimages. Source: $\langle$ http://jasoncantarella.com/downloads/ucid.v2.tar.gz〉.

[20] Public-domain test images for homeworks and projects. Source: 〈https://homepages.cae.wisc.edu/ ece533/images/〉.

[21] SeedArea. Rose - seeds (Mix-color). Source: $\langle\mathrm{http} / / / \mathrm{www}$.seedarea.com/rose-seeds/136-rose-seeds-mixcolor.html $\rangle$

[22] ImpulseAdventure. JPEG compression quality from quantization tables. Source:

〈http://www.impulseadventure.com/photo/jpegquantization.html $\rangle$.

[23] Winkler S, van den Branden Lambrecht CJ, Kunt M. Vision and video: Models and applications. In Book: van den Branden Lambrecht ChJ, ed. Vision models and applications to image and video processing. Boston: Springer; 2001: 201-229.

[24] Poynton Ch. Digital video and HDTV: Algorithms and interfaces. US Morgan Kaufmann Publishers; 2003.

[25] Uhrina M, Bienik J, Mizdos T. Chroma subsampling influence on the perceived video quality for compressed sequences in high resolutions. Adv Electr Electron Eng 2017; 15(4): 692-700.

[26] Ahmed N, Natarajan T, Rao KR. Discrete cosine transform. IEEE Trans Comput 1974; C-23(1): 90-93.

[27] Narasinha NJ, Peterson AM. On the computation of the discrete cosine transform. IEEE Trans Commun 1978; COM-26(6): 966-968.

[28] Lee BG. A new algorithm to compute the discrete cosine transform. IEEE Trans Acoust Speech Signal Process 1984; ASSP-32(6): 1243-1245. 
[29] Mandyam GD, Ahmed NU, Magotra N. DCT-based scheme for lossless image compression. Proc SPIE 1995; 2419: 474-478. DOI: 10.1117/12.206386.

[30] Madenda S, Pengolahan citra dan video digital: Teori, algoritma dan pemrograman Matlab. Jakarta: Erlangga, 2005 .
[31] Gonzalez RC, Woods RE. Digital image processing. $2^{\text {nd }}$ ed. Prentice Hall; 2002.

[32] Madenda S, Missaoui R. A new perceptually uniform color space with associated color similarity measure for contentbased image and video retrieval. Proceedings of Multimedia Information Retrieval Workshop, $28^{\text {th }}$ annual ACM Sigir Conference 2005; $1-8$.

\section{Authors' information}

Sarifuddin Madenda is a researcher and professor at Gunadarma University, Indonesia. He was born in Raha, Indonesia 7th April 1963. He finished his: B.S degree in Physic Instrumentation at University of Indonesia in 1989; M. S. degree in Electronics from INSA-Lyon, France in 1992; and Ph.D degree in Electronics and Image Processing from Universite de Bourgogne, France in 1995. He is also lecturer at UQO, Quebec - Canada since 2003. Actually, he is Director of Doctoral Program in Information Technology. His research interests are focused on image and video processing, multimedia data compression, content based image and video retrieval, steganography (encryption, decryption, coding) and decoding of multimedia secret documents, real time system architecture (FPGA and ASIC design).

E-mail: sarif@staff.gunadarma.ac.id.

Astie Darmayantie was born in Jakarta, Indonesia 27th March 1990. She acquires her Bachelor Degree in Computer Science 2011. She finished her master in 2013, in which brings her to be entitled as Master in Information System Management from Universitas Gunadarma and Master in Computer Vision and Robotics from Universite De Bourgogne. She completed her doctoral degree in information technology in 2018. Her research interests vary from machine learning to health informatics and socio-technical aspects in technology. E-mail: astie@staff.gunadarma.ac.id.

Received July 2, 2020. The final version - February 16, 2021. 